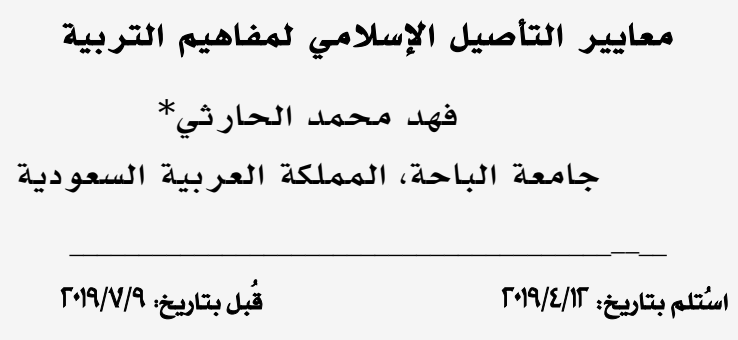

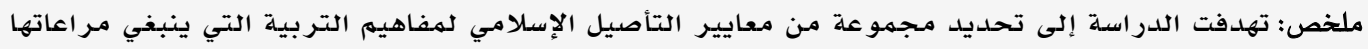

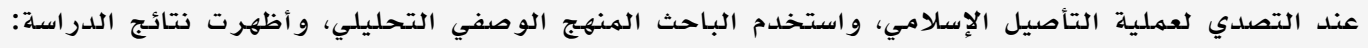

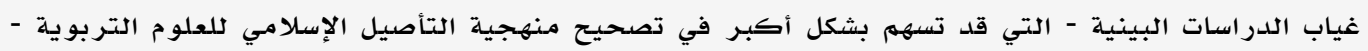

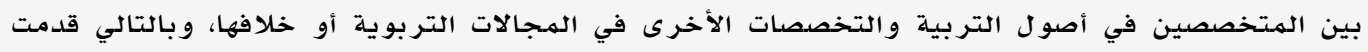

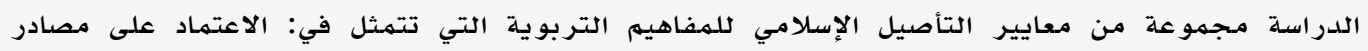
التربية الإسلامية، الالتزام بقواعد الاستتباط والاستدلال في المنهجية الإسـلامية، القدرة على ملى نقد مرويات

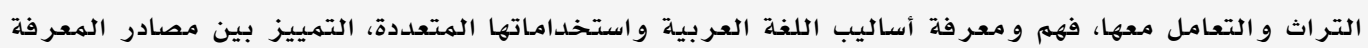

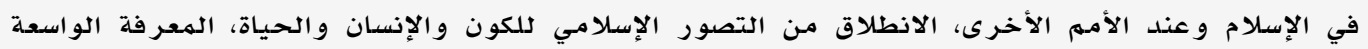

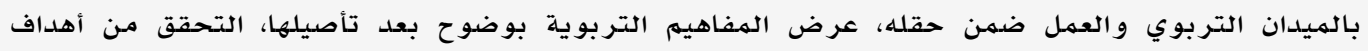

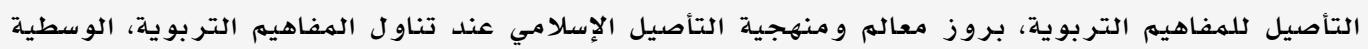

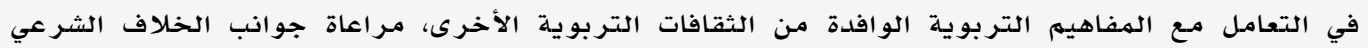
و انعكاسـه على التطبيقات التربوية. وقد خلصت الدراسة إلى مجمهوعة من التوصيات في ضوء فو ما توصلت إليه من نتائج

\author{
كلمات مفتاحية: معايير ، التأصيل، المفاهيه، التأصيل الإسلامي، مفاهيهم التربوية.
}

\title{
Standards of Islamic Rooting for the Concepts of Education
}

Fahad M. Alharthi*

Albaha University, Saudi Arabia

\begin{abstract}
The study aimed to identify a set of Islamic standards for the educational concepts that should be taken into account when addressing the process of Islamic rooting. The researcher used the analytical descriptive method, and the results of the study showed the absence of Interdisciplinary studies, which may contribute more to correcting the methodology of Islamic rooting for educational sciences, among specialists in the origins of education and other disciplines in the educational fields or otherwise. Thus, the study presented a set of Islamic Rooting standards for the educational concepts which are: reliance on sources of Islamic education, adherence to the rules of derivation and reasoning in Islamic methodology, ability to critique and deal with the heritage tales and understanding and knowledge of Arabic language methods and their multiple uses. The distinction between the sources of knowledge in Islam and other nations, starting from the Islamic perception of the universe, man and life, extensive knowledge in the field of education and work within the field. Results also indicate the presentation of educational concepts clearly after rooting them, verification of rooting objectives of educational concepts, emergence of features of the methodology of Islamic roots when dealing with educational concepts, averageness in dealing with educational concepts coming from other educational cultures, taking into consideration the aspects of the legal dispute and its reflection on educational applications. The study concluded with a set of recommendations in the light of its findings
\end{abstract}

Keywords :Standards, rooting, concepts, Islamic rooting, educational concepts.

*aaamn@hotmail.com 
الغربية دون تمحيص أو تحليل، أو بسبب

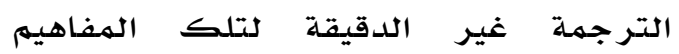

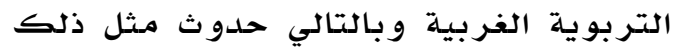

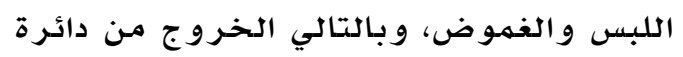

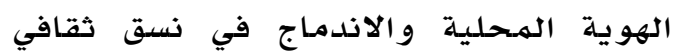
مغاير لو اقعهـ.

إن سيادة المفاهيهم الغربية أدّت بفعل شيوعها

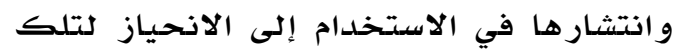

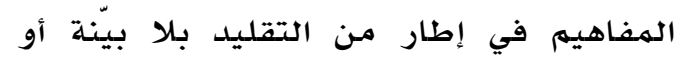

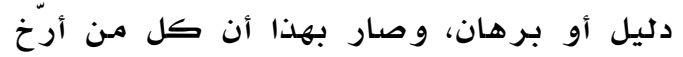

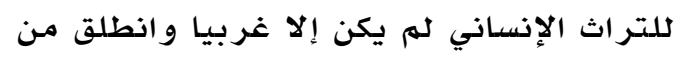

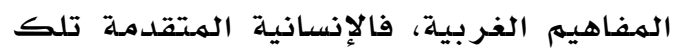
فقط النابعة من الحضارة الغربية (إسماعيل،

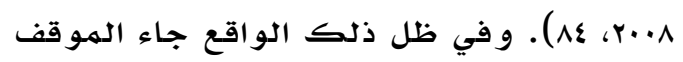

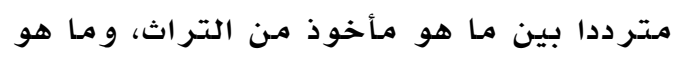

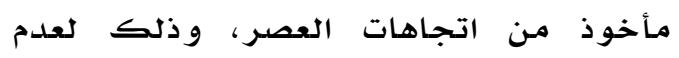

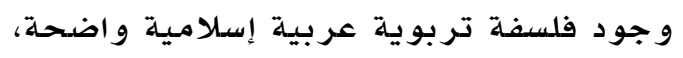

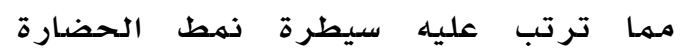
الغربية وتقاليد الدو لة الهستعهمرة (الميمان، (19 r. r. r

إن الدعوة إلى توجيه العلوم توجيها إسلاميا،

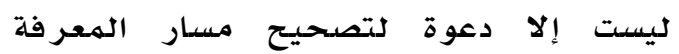

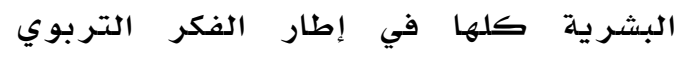

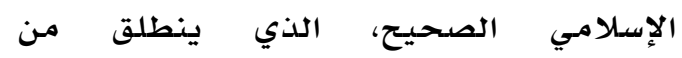

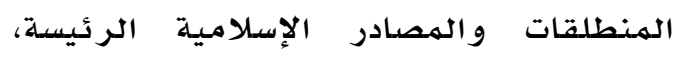

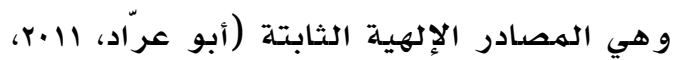

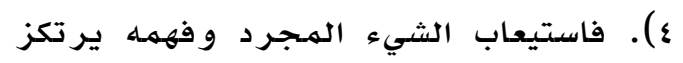

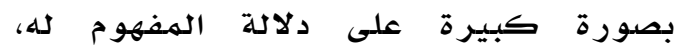
فاللفظ يحمل في طياته المعنى الحقيقي

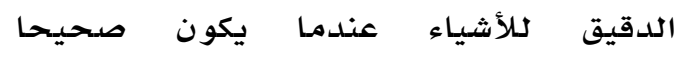
و منسجما مـع فلسفته التي ينطلق منها. إن تحليل المفاهيم لأي فرع أو حقل معر في

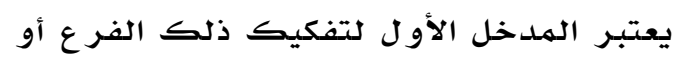

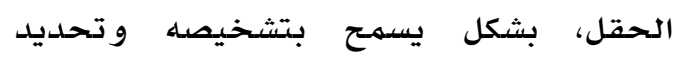

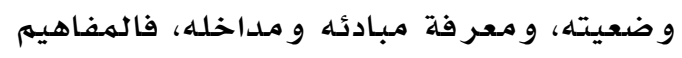

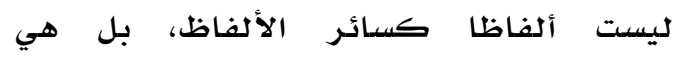
مستودعات كبرى للمعحاني، و الدلالات، كثيرا

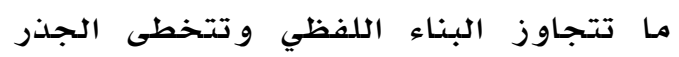

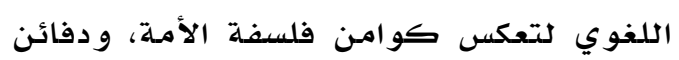

تستمد التربية الإسلامية فكرها ومبادئها من

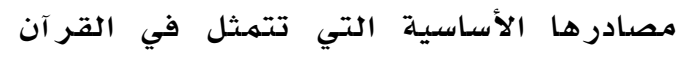

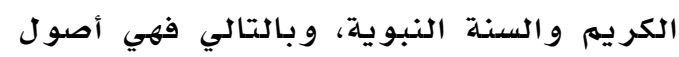

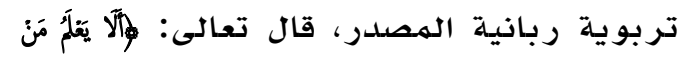

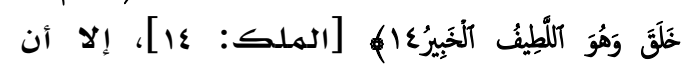

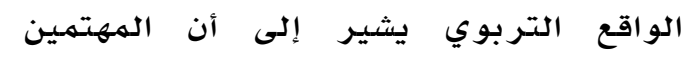

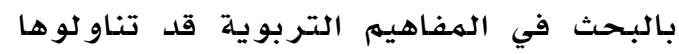
في ضوء الفلسفة الغربية، فنقلوها إلى البيئة

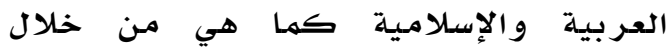
الترجمة دون تأصيل أو توجيه إسـلامي، وهو هو

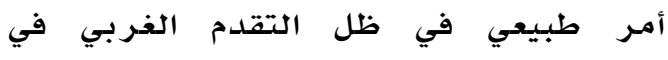
الدراسـات التربوية في مقابل التخلف العلمي

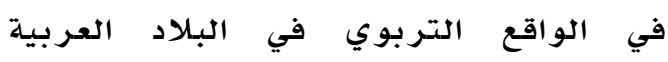

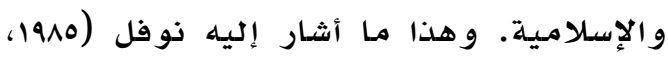

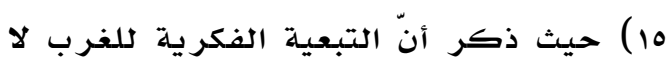

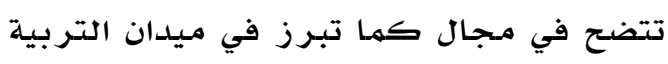
والفكر التربوي، وأن السبب الأسساسي في في في في

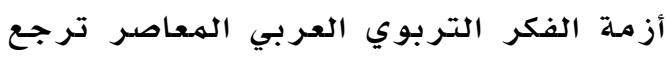

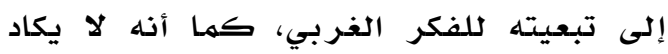

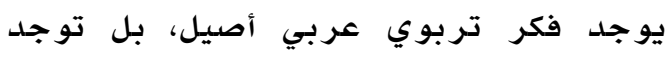

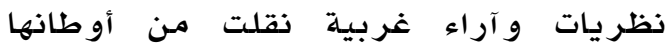

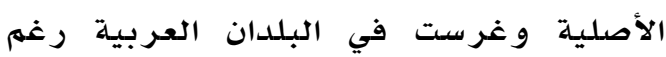

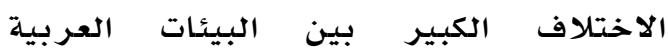

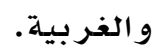

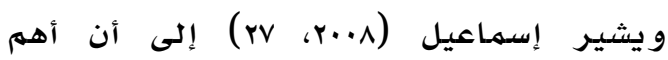

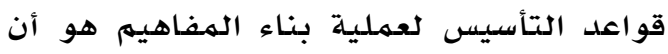
(المفاهيم عملية في صميم قضية الهوية).

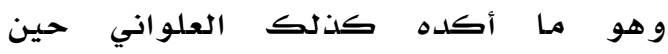

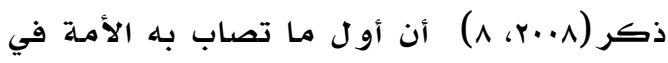

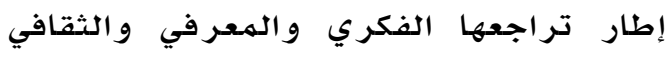

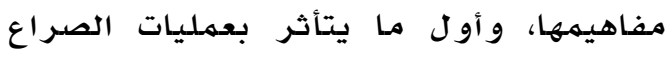

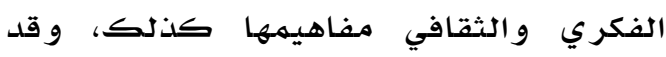

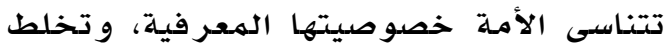

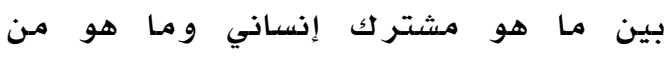

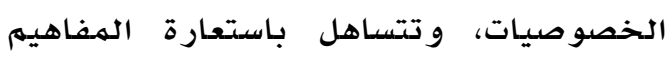

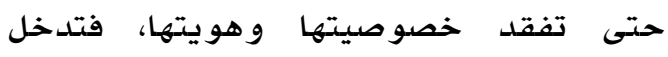
مفاهيمها دائرة الغموض وفئ والارتباك.

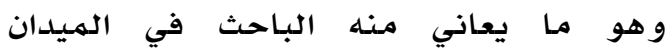

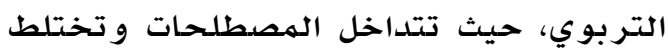
المفاهيم، إما بسبب النقل عن الدريب اسلات 
العلوم المختلفة، وذلك مـن خلال التأمل و التدبر في القر آن الكريم و الحديث الشريف

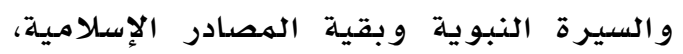

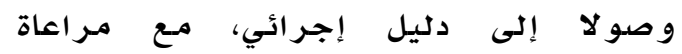
المتغير ات و المستجدات.

و للذا تتعالى النداءات لدى الههتمين بالتربية

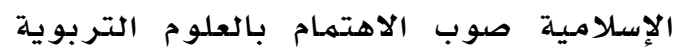
و التركيز على إعادة صياغتها صياغة تتفق

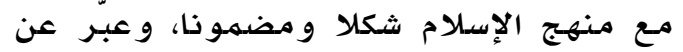

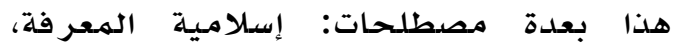

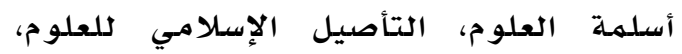

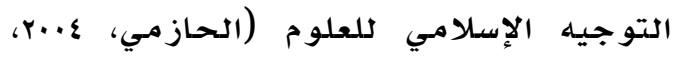

و مجال الدراسـات الأصولية من أهم مـجالات الهات

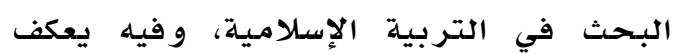
الباحث على القر آن الكريم والسنـة النبوية

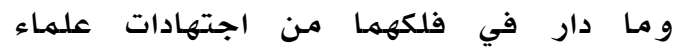

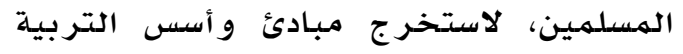

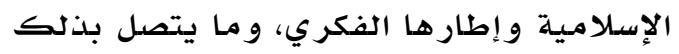
من أهداف وقيم وطرائق تربوية والإسية وتعليميلة، وكذلك استنباط ومناقشة عدد من الأفكار

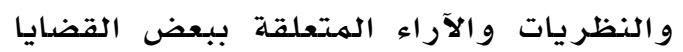
و المفاهيم التي يحفل بها عالهم التربية

$$
\text { و التعليه (النقيب، ع...r، 19). }
$$

و مـع ظهور العديد من الدراسات في التربية

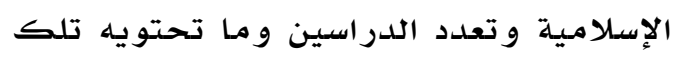

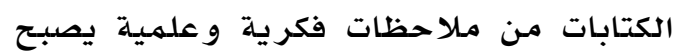
من الضروري أن تظهر دراسـات علمية معمقة تستهدف تقويم العمل البحثي الذي الذي النهي تم حتى الآن في هذا الهيدان من حيث

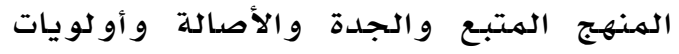

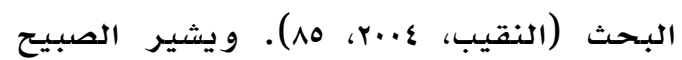

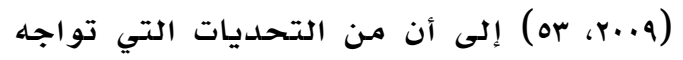
الباحثين في التأصيل تحديد مسلمـات الإطار الهار الإسـلامي، و توظيف هذه الهسلهمات في البحث

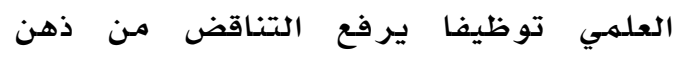
البـاحث المسلميم.

إن قضية التأصيل تستهدف أول ما تستهدف

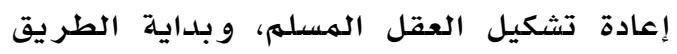

تراكمات فكر ها و معر فتها و ما استبطنته

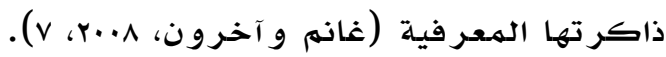
فالمفاهيم هي أساس البناء لقيام أي علهم، و لا

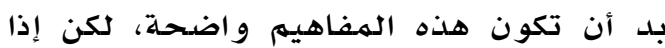
لحق بها شيء مـن الغموض أو التحريف أو التغيير بسبب التساهل في استعارة أو ترجمهة

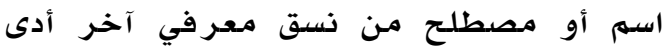
ذلك إلى حدوث خلل في هذه المفاهيم، و بالتالي خلل في بناء العلهم نفسـه (الميمان،

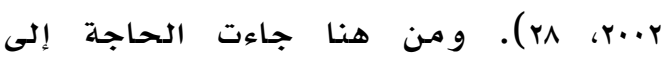

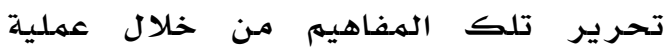
التأصيل الإسلامي الدقيق لها، بعد إخضاعها

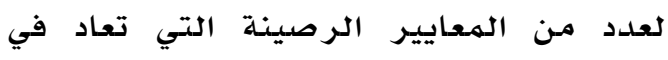

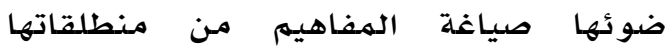

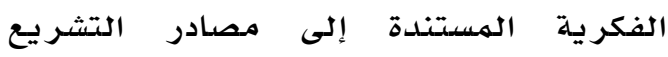

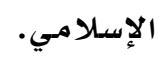

و تتضمن عملية التأصيل توليد الأفكار

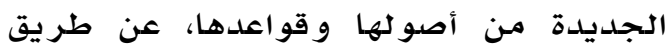
الاستدلال الاستنباطي، فالفكر المؤصل هو هو

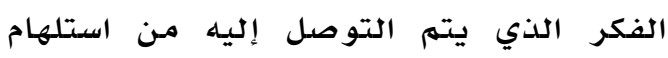
الأصول أولا، والاشتقاق من هذه الأصدول ثانيا، فكل فكر لا يتصف بذلك هو فكر اولاون غير

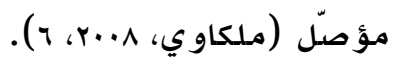

ويقوم العمل البـحثي في مجال أصدول التربية على مصادر التشريع الإسلامي، ووفي

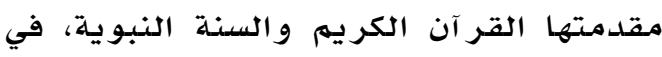
إطار العمل على صياغة العلوم التربوية في ضوء الرؤية الإسلامية لأهم الأهم القضايا

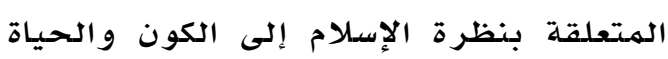
و الإنسان و المعر فة.

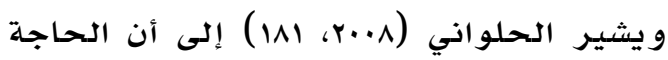

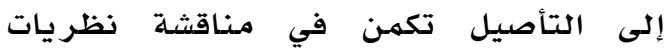
و مبادئ العلوم التي نشأت في البيئة الغربية،

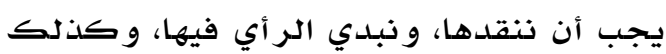
نقد و تقويم السلو كيات و الممـار سات الحالية

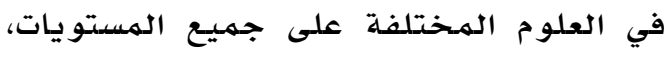
مـع اقتراح التعديلات الكلازمهة، وبيان الظروف

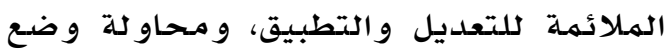

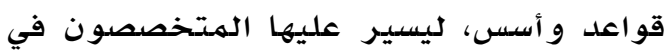




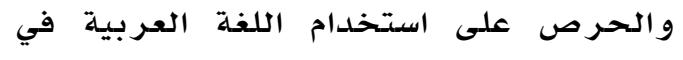

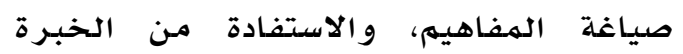

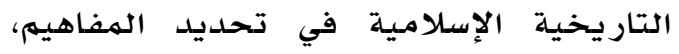

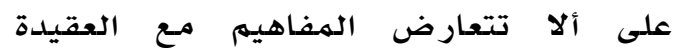

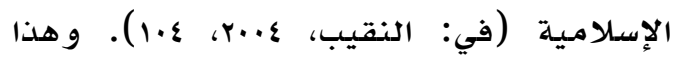
الطرح يؤكد على ضرورة أن ينطلق البحث الاسيه

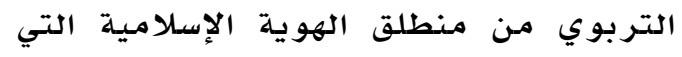

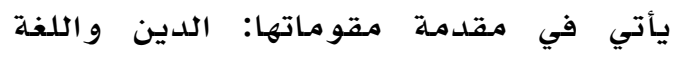
و التاريخ و القيه و الثقافة. إن النظريات والآراء والأفكار التربوية

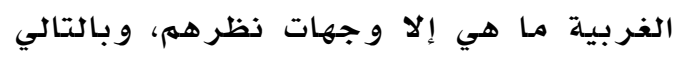

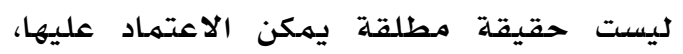

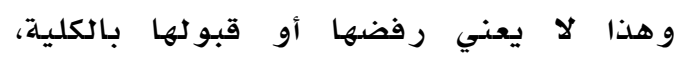

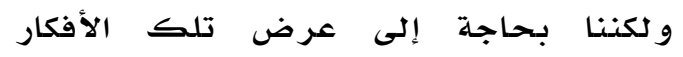

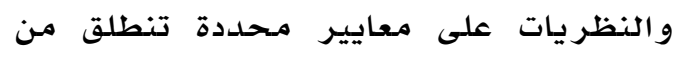

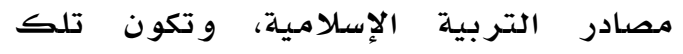
المصادر هي الأصل والهموجه لتلك الهاله الأفكار

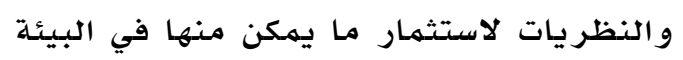

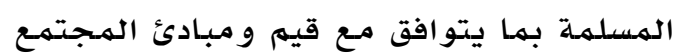
الهسلهم. و في هذا السياق أجرى العيسى (17. إ) دراسـة

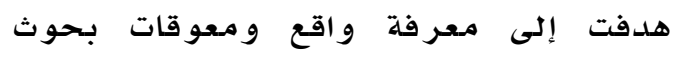

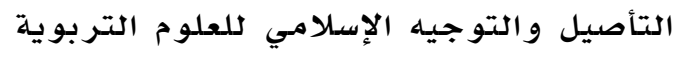

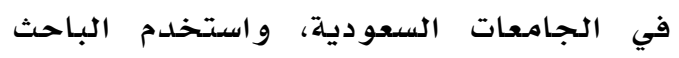

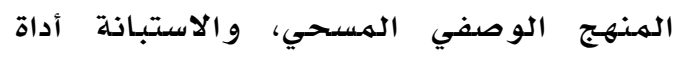

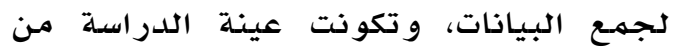

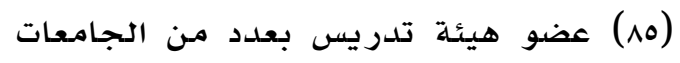

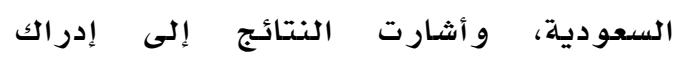

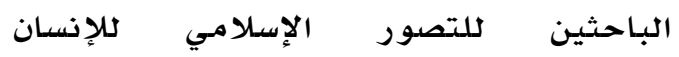

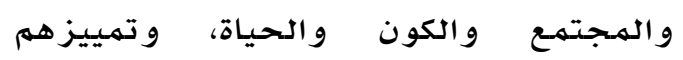
بهصادر المعرفة في الإسـلام و عند الغرب. في حين هدفت دراسة العلياني (·r.r) إلى محاولة الإسهام في تأصيل الفكر التربوي

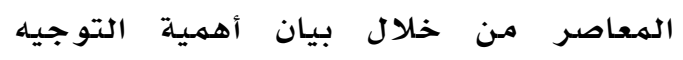

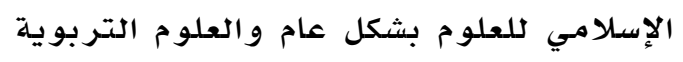

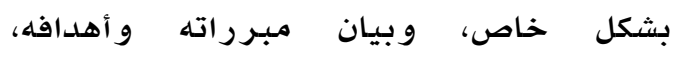

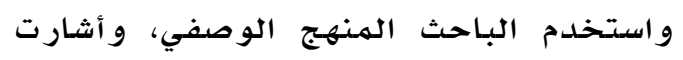

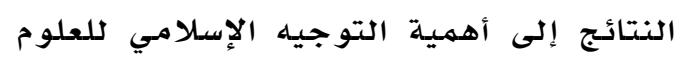
التربوية في الحفاظ على الهوية الإسلامية الهية الإسية
لإعادة تشكيل العقل المسلهم تتمثل في إعادة بناء مجموع الهفاهيم الأساسية التي يقوم

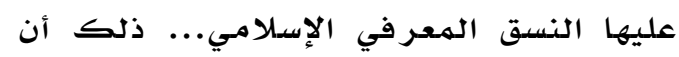

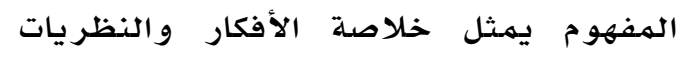

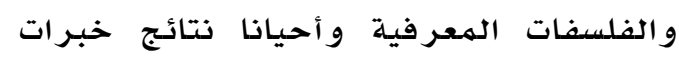

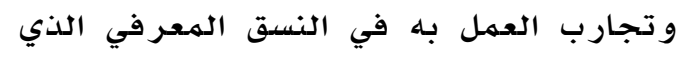

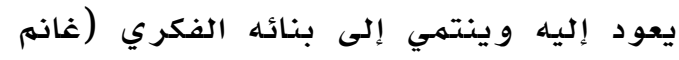

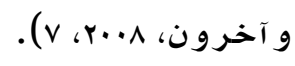

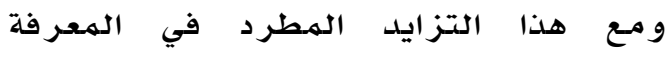

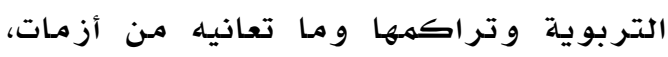
فلابد و أن يقف الهـتهـع التربو بوي موقفا جادا

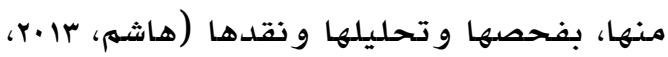

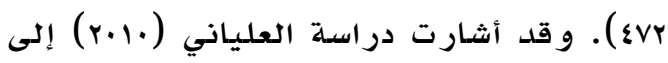
أهمية التوجيه الإسـلامي للعلوم التربوية في

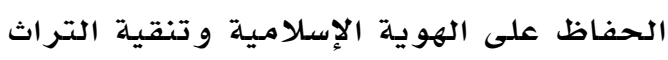
التربوي مـما علق به من تلوث فكري، كما

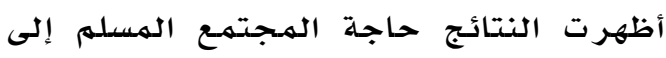

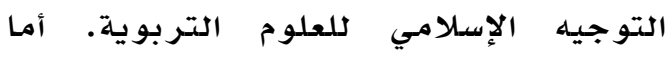

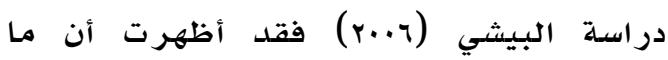

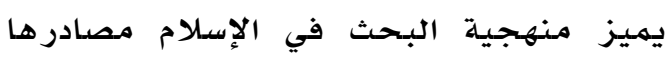

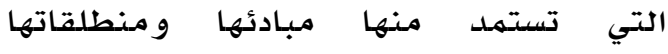

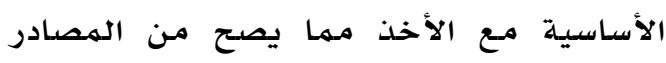

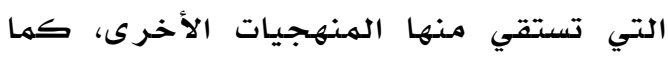
أكدت على وجود تبعية فكرية في مناهج البحث في العالم العربي. في حين أشارت

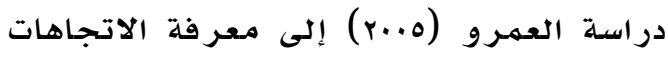

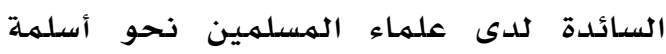

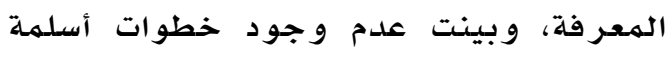

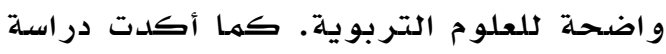

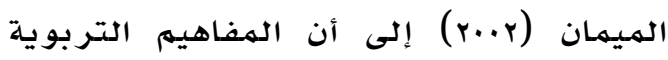
تعرضت لعمليات التقويض المـختلفة مثل:

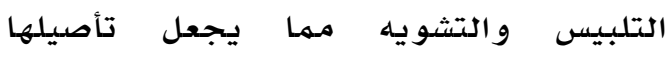
ضرورة شر عيلة.

ومن المهم ضرورة مراجعة جميع المفاهيم

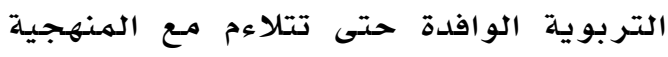

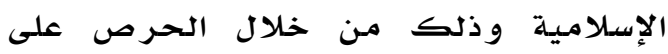
إحياء المفاهيم القر آنية و الواردة في في حلديث

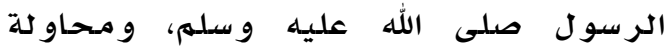

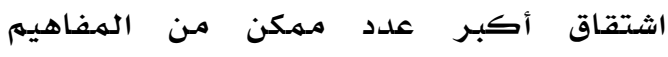

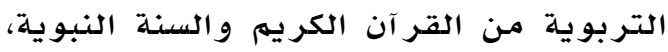


يتضح من خلال من سبق عرضهـ من دراسـات أنها تناولت قضية التأصيل الإسلامي للتربية

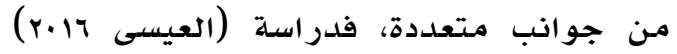

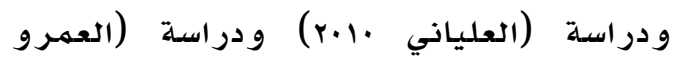

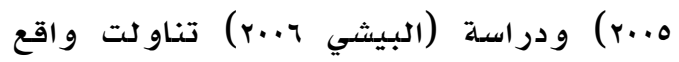
التأصيل الإسلامس للتربية و معوقاته و أهميته

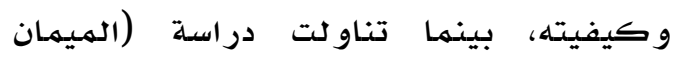

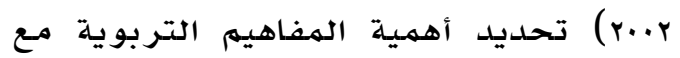
خطوات مقتر حة لتأصيل مفهو مي التربية التهاية

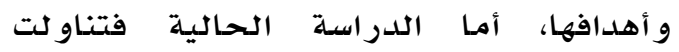
التأصيل الإسلامي للمفاهيم وقدما، ومت معايير مقترحة للتأصيل الإسـلامي لمفاهيم التربية، واتفقت جميع الدراسـات في استخدام المنهج

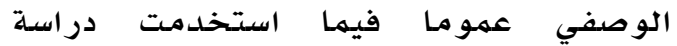

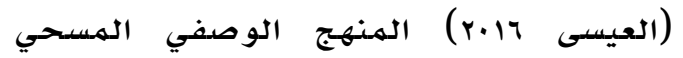

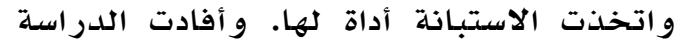

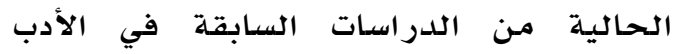
النظري بشكل عام وفي صياغة المعايير

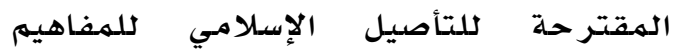

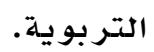

أسئلة الدراسة

يمكن تحديل مشكلة الدراسة في السؤال

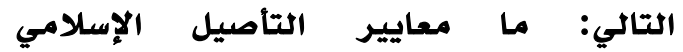
للمفاهيم التربويةو مائ و يتفرع من السؤال الرئيس الأسئلة الآتية: ا. ما المقصود بالتأصيل إسلامي كلمفاهيم التربوية؟

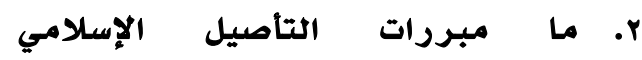
للمفاهيم التربويةء

r. ما أهم معايير التأصيل الإسلامي للمفاهيم التربوية؟

أهداف الدراسة

تسعى هذه الدراسـة إلى تحديد مجمموعة من

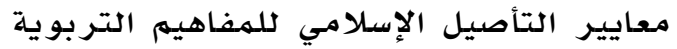

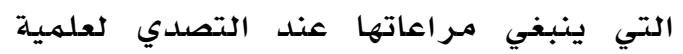

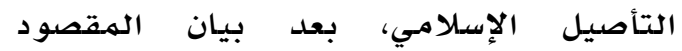

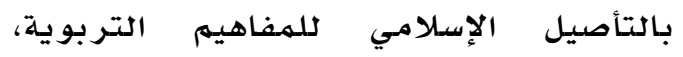

و تنقيـة التراث التربوي مهما علق به من تلوث فكري، كما أظهرت النتائج حاجـة المـتهـع المسلهم إلى التوجيه الإسلامي ل للعلوم التر بو ية.

كما هدفت دراسة البيشي (r..r) إلى التعرف على المفاهيه الأساسية في عملية

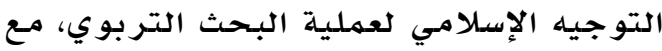

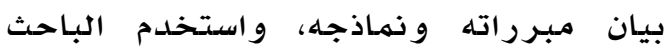
المنهج الوصفي، وأظهرت النتائج أن ما يميز

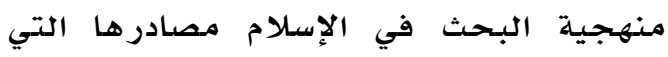

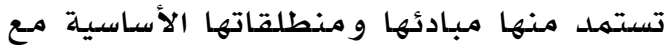
الأخذ مها يصـح من المصادر التي تستقي منها المنهجيات الأخرى، كمها تؤكس الدر اسلة على وجود تبعية فكرية في مناهـ البحث في

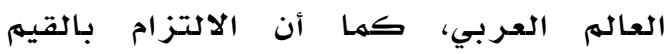

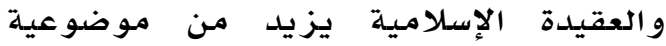
الباحث.

أمـا دراسـة العمـرو (r...0) فهدفت إلى كيفية التوجيه الإسـلامي للعلوم التربوية، واستتخدم

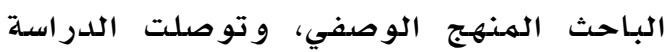
إلى تحديد خطوات أسلهمة وتأصيل العلوم

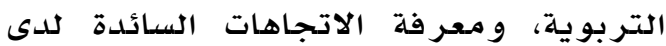
علماء المسلمين نحو أسلمة المعرفة، وتبين عدم وجود خطوات أسلمة و اضحة للعلوم

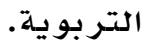
و هدفت دراسـة الميمان (r..r) التي هدفت

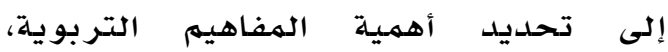
وتوضيح ماهية التأصيل الإسلامي للمفاهيه،

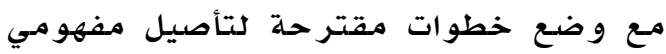
التر بية و أهدافها، واستخلدمت الباحثة المنهج الوصفي، وأظهرت النتائج أن المفاهيم

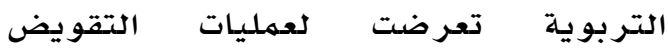
الهختتلفة مثل: التلبيس والتشويه مها يجعل

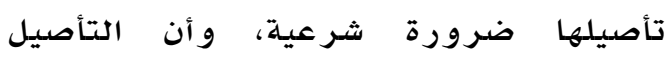

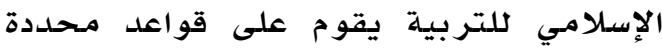
تتمثل في نصوص القر آن الكريه، و الحديث الشريف، وكتب التراث الإسـلامي و الكتابات العربية و الغربية المعاصرة. 
تحليلي يحاول ربط الفكرة الفرعية بأصلها

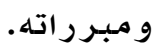

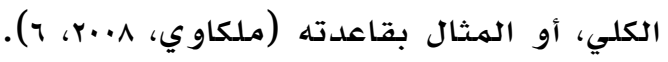
أهمية الدراسة

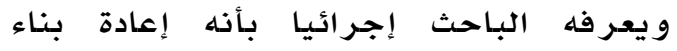

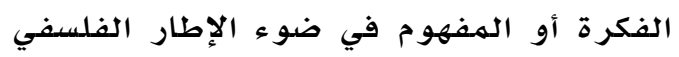

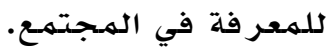

المفاهيم: المفهوم هو لهجئ مجموعة الصفات

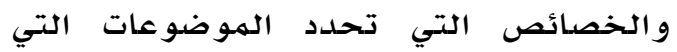
ينطبق عليها اللفظ تحديدا يكفي لتمييزها

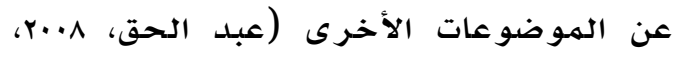

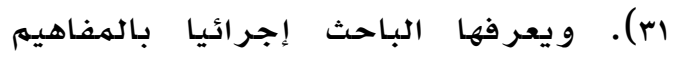

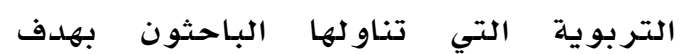
تأصيلها إسلاميا في دراساتهم.

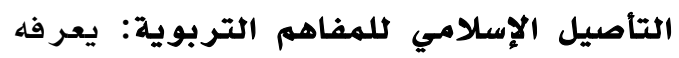
الباحث إجرائيا بأنه إعادة صياغة المفاهيم الإناهيم

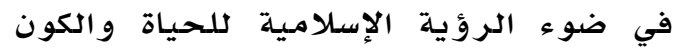

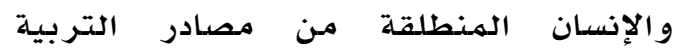

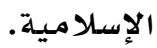

\section{منهجية الدراسة}

استخدم الباحث المنهج الوصفي في أسلوبه

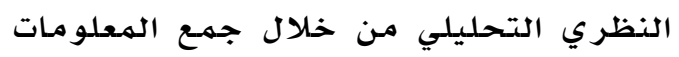

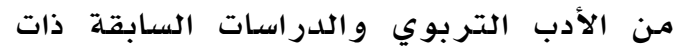

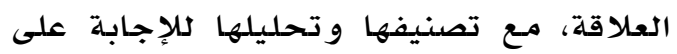
أسئلة الدار اسلة.

\section{حدود الدراسة}

اقتصرت الدراسة على تحديد معايير التأصيل

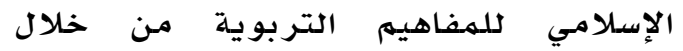

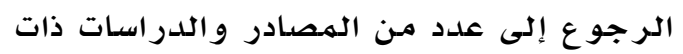

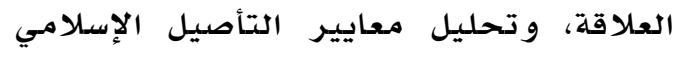

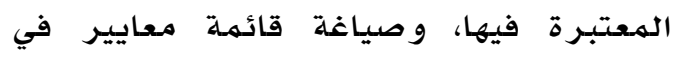
ضوء مصادر التربية الإسدلامية.

\section{أولا: التأصيل الإسلامي للمفاهيم التربوية:}

يتناول الباحث مدخلا للمصطلحات المتعلقة بالتأصيل الإسلامي للتربية، مع بيان إندان بداياته،

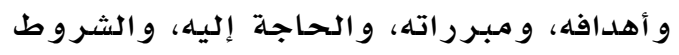
التي ينبغي أن تتوفر فيمن يتصدى لله.

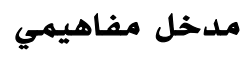

جاءت كلمة (تأصيل) من مفردة (أصل) مليل

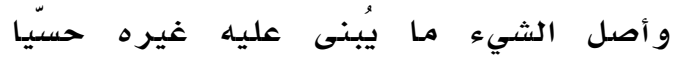

الأهمية النظرية: قد تسهر هذه الدراسة في

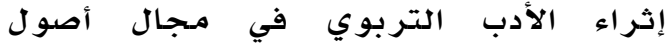

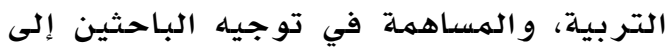

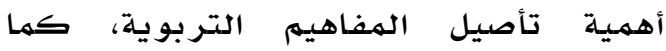
تكتسب هذه الدراسة أهميتها من أهمية

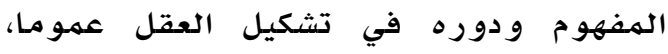
والحاجة إلى التأصيل الإسلامي للمفاهيه

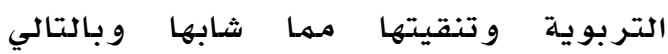
المحافظة على الهوية.

الأهمية التطبيقية: قد تساعد الدراسلة على الإبلى

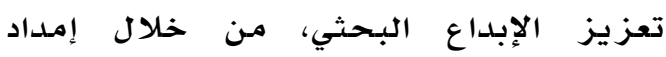

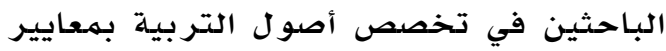

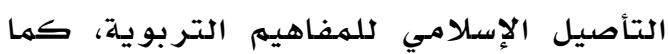
قد تساهم في تطوير البحث العلهي في العيائ الميدان التربوي، وتقديم صورئ صورة واضحة

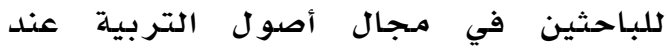

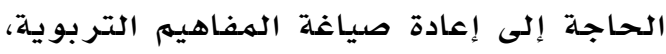

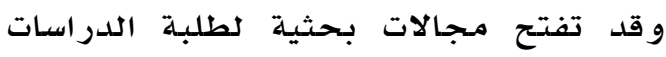

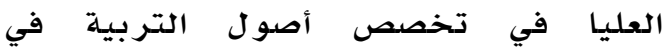
الجحامعات.

\section{مصطلحات الدراسة}

معايير: المعيار في اللغة ما يوزن به الشيء الثهاء

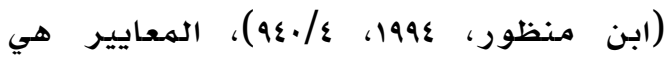

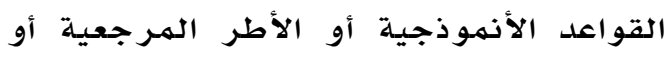

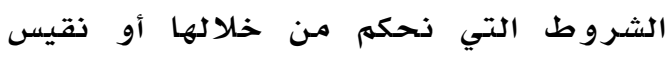

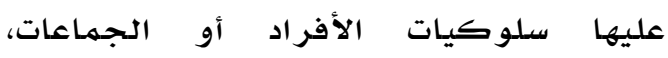

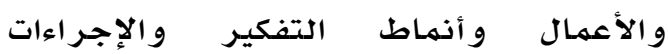

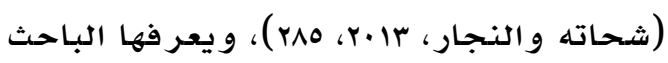

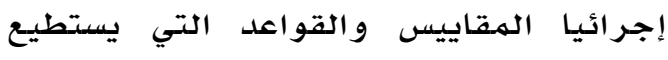

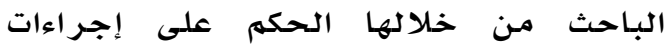

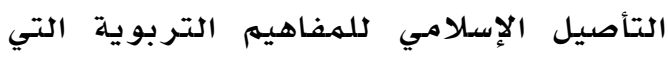

يتخذها الباحثون في دراساتهم التأصيلية.

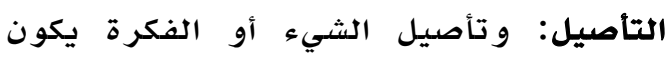

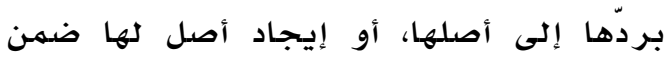

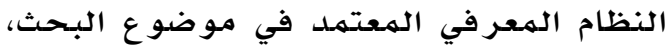

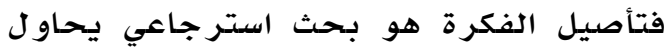

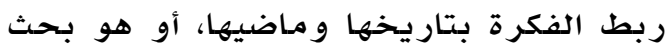


المفهوم بين الفهم والوهم هو مـا مؤثر بلدرجة كبيرة في الوصول إلى نتائج دقيقة لبعض الدراسـات و البحوث؛ لاعتمـادها بصورة إنورة كبيرة على الهعنى الذي في ذهن الباحث

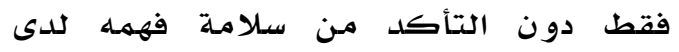
الجمبيع. ويقصد بالهفاهيم التربوية: الأفكار التجريدية التي تجمـع بين التصور الذهني

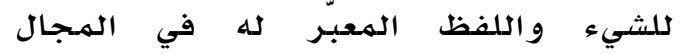

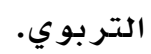

إن مفهوم (التأصيل الإسلامي) مثله مثل مثل الإميل

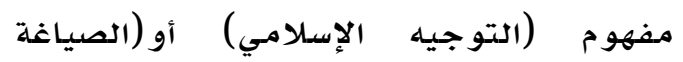
الإسلامية) أو (الإسلامية) أو (الأسلمة الإسة) و والتي تم توليدها بمجمو عها داخل النسق الهعر في الهي

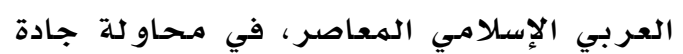

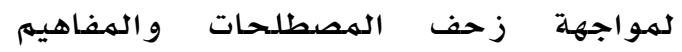
الدخيلة، التي اكتظت بها الساحة المعر فية والهة

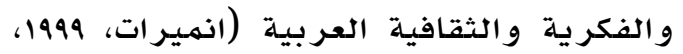

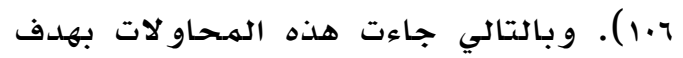
بناء منهجية تأصيلية إسلامية لإعادة صياغة المفاهيم والعودة إلى المنطلقات الأصلية للمعر فة الإسـلامية.

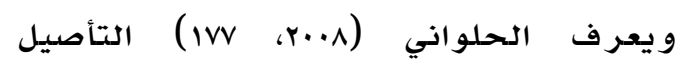

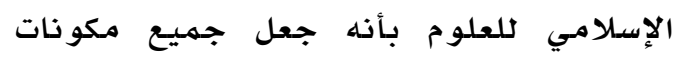
و عناصر أي فرع من فروع العلهم منبثقا من

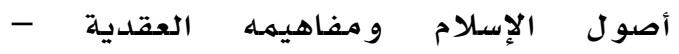

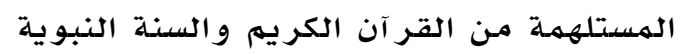
وبقية المصدادر الشرعية - وغير مخالفة لها،

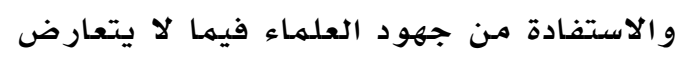

$$
\text { مـع تلك الأصول. }
$$

و إذا كان التأصيل الإسـلامي للعلوم التربوية

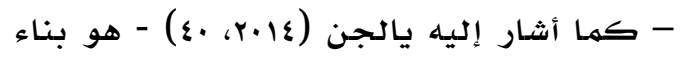
تلك القضايا والأفكار في الهـال الترنال التربوي

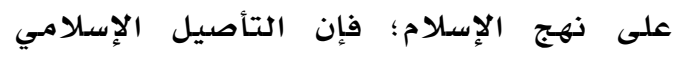
لمفاهيم التربية هو إعادة صياغة المفاهيم و بنائها على نهج الإسـلام أي في ضونه إعاده الرؤية الإسـلامية للحياة و الكون و الإنسـان.

إنه التصور العام الذي ينهّ عن رغبة "عن
و معنويا، و أصل الشيء أسـاسـه الذي يقوم

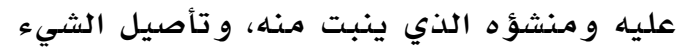

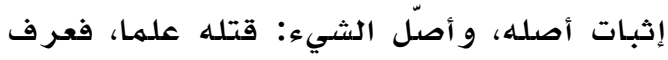
أصله، ورأي أصيات أهله، وأهل الثيء أصل (ابن منظور،

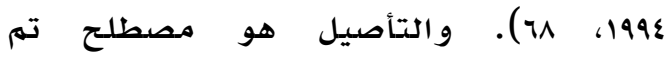

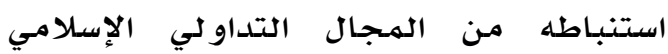
العام، الذي يهدف إلى قيام تصدور إسـلامي للبناء الفكري و العلهي، يكون بمقدور إهـ إعادة بناء الذات والدفع بها إلى الإبداع والإنتاج،

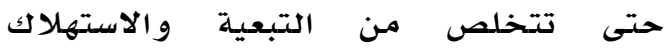

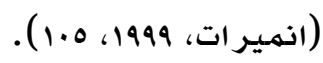

أما كلمة (المفهوم) فمأخوذة من الفهم، و الفههم معرفتك الشيء بالقلب، فهمهـ فهما:

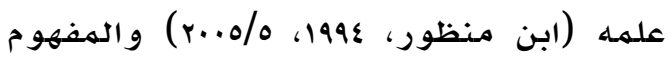

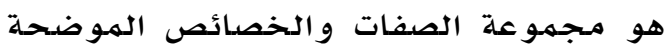

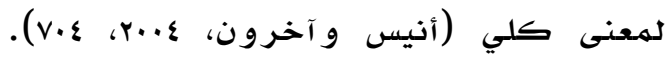
و المفهوم اصطلاحا: هو الصورة الذهنية

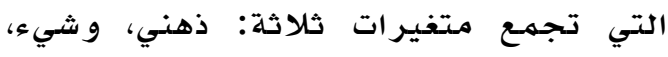
ولفظ معبر عن ذلك ذالك الشيء، فالصورة الذهنية التي يدل عليها اللفظ تسهى مفهوما مدئ

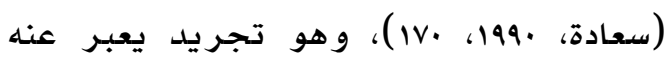
بكلمة أو رمز يشير إلى مجموعة مة من الأشياء أو الأنواع التي تتميز بسمات وخصائص

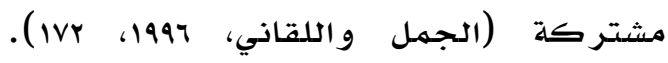

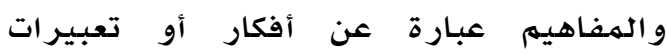

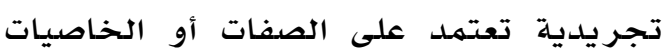

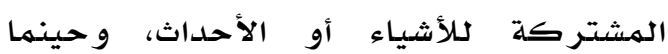
توضع الهفاهيم مـع بعضها البعض لثرح ظاهرة معينة فإنها تدعى بالنظريات (أونجل،

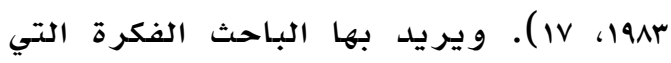
يعبّر بها عن الشيء بلفظ محسدد مجرير. و الهفاهيم و التعر يفات هي التي تستخدم في صياغة الفروض النظرية بصدورة مباشرة أو غير مباشرة ومن ثم تحدد اتجاه البحث. و لعل الاختلاف في - في المنهجيات إنما هو

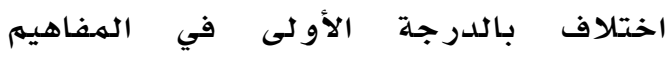
المستخلدمة. و لذا ينبه الباحثون إلى خطورة الدورة استخدام المفاهيهم والتعريفات الوافدة دون التأكد من مدى سلامتها وصحتها إسلاميا

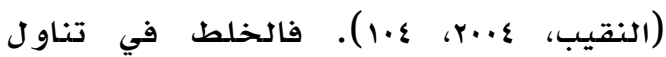




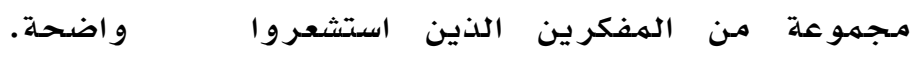

بدايات التأصيل الإسلامي للتربية

نشأت العلوم الإنسانية في الغرب واكتملت مناهجها على يد أوجست كونت ووفرويد

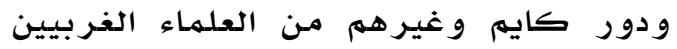

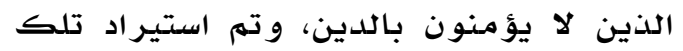

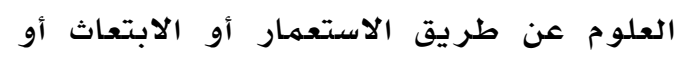

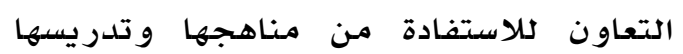

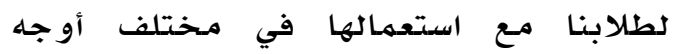

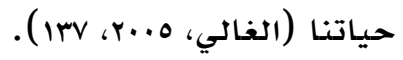

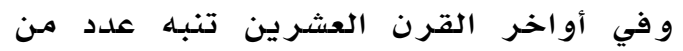

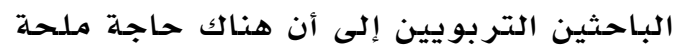

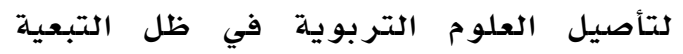
الفكرية التي ظلت تسيطر على المفاهيه التربوية نتيجة للعديد من العوامل فئ في تلك تلكي

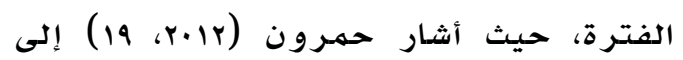

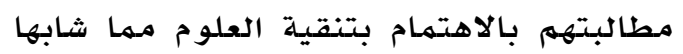

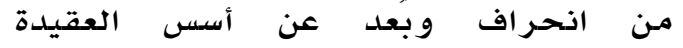

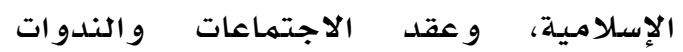

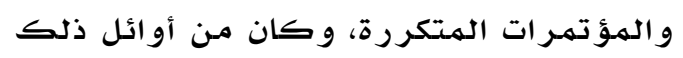

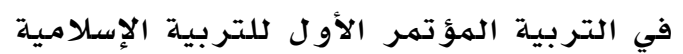

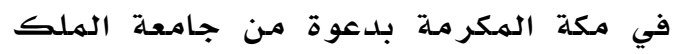

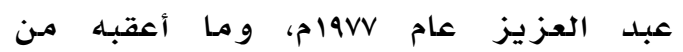

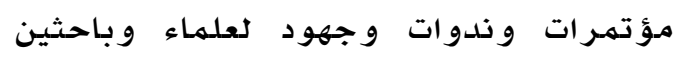

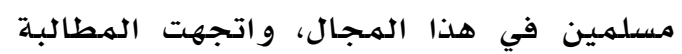

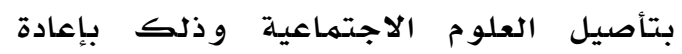
بنائها على أسس وذهيل العلوم الدين الإسلامي.

فيما يشير الصنيـ (r/r.r، VV) إلى أن حركة

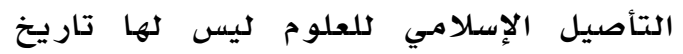
محددد، ولهم يكن واردا لدى على الدماء المسلمين

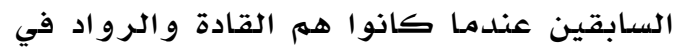

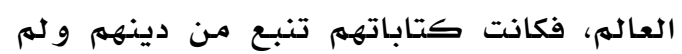

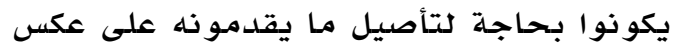

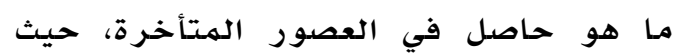
أصببح العلماء المسلمون يتبعون غيرهل هم، لذا هاهي

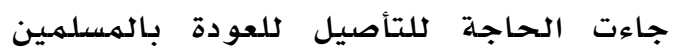
لأصو لهم الهعر فية الإسلامية. خطورة المسار الفكري و الثقافي و العلمي

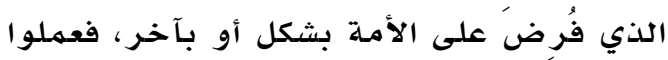

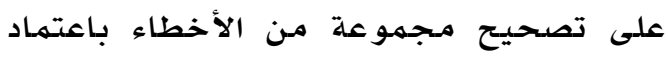
منهجية النقد الذاتي انطلاقا من من الأصول

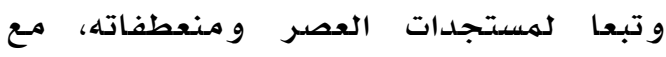
الاستئناس بهفاهيه السابقين التي انطلقت

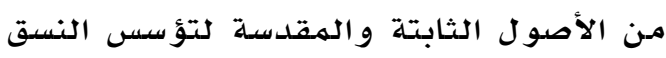

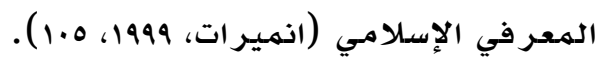

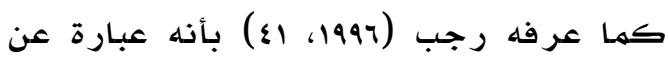

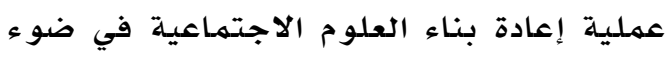

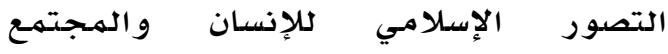
و الوجود، وذلك باستخدام منهج يتكامل فيه

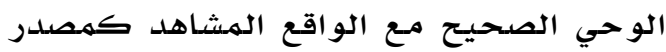

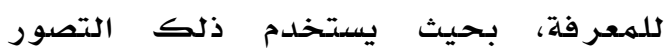
الإسلامي كبإطار نظري لتفسير المشاهدات

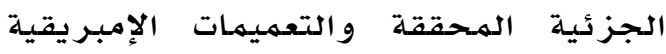

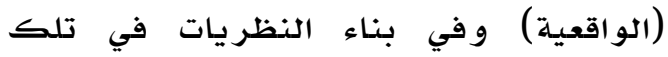

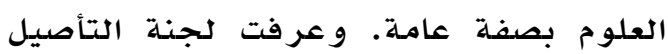

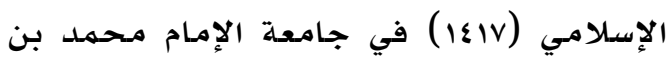
سعود التأصيل الإسلامي للعلوم الاجتيتماعية بأنه: تأسيس تلك العلوم على ما يلائهها في

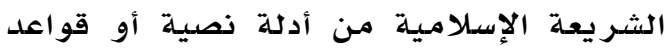

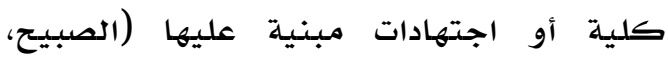

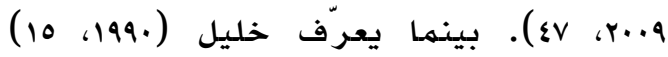

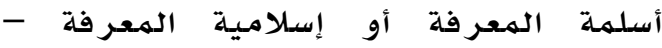
ويقصد بها التأصيل الإسلامي للعلوم - بأنها مـمارسلة النشاط المعر في كشفا، وتجميعا،

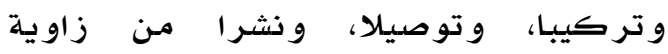
التصور الإسلامي للكون والحيا، ولحياة والإنسسان.

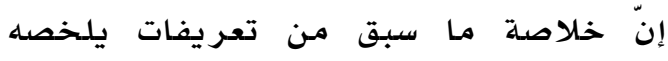

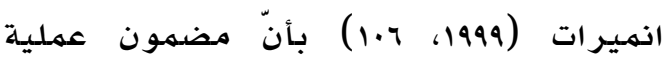

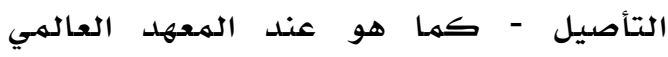

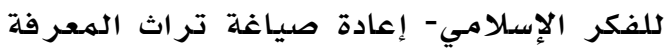

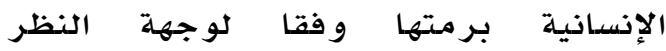

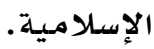

إن" التأصيل الإسـلامي للمفاهيم التربوية يتمثل في إعادة بناء المفهوم في ضوء نظرة

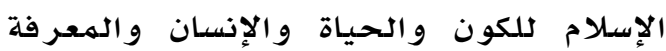
وفق منهج تكاملي في إطار معايير علمية 
مهمم لتأسيس منهج تربوي في ضوء النظرية التربوية الإسـلاميهة، يسهم في مناقشة قضايا المجتمهع المسلهم بعيدا عن التبعية الفكرية. و في ظل التحديث الهعاصر للعلوم التربوية

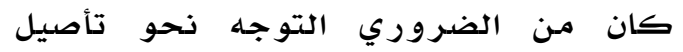

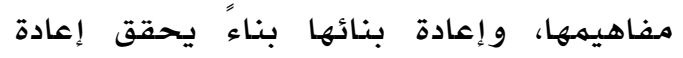
صياغتها في ضوء منهج الإسلام، حتى يمكن

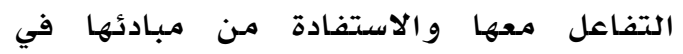
الوقع الحيـاعي.

و مهما يدعو للتأصيل أن القر آن الكريم ليس

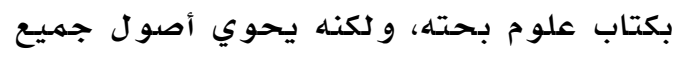

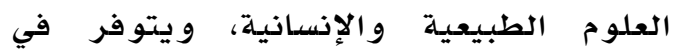
القر آن والسنـة - من الصديد والهيه والثبات و القوة

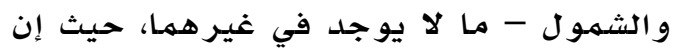

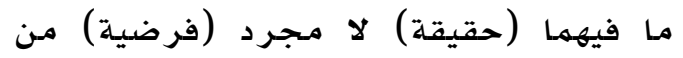
الفرضيات التي تحمل الصحة و الخطأ، وبما مانها

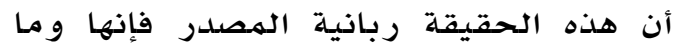

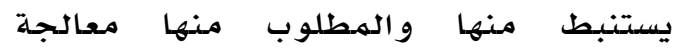
مشكلات البشر وإدارة حياتهم، تكون شاملة

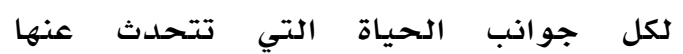

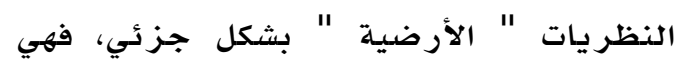
تعطي كل جانب ما يستحقه دون أن يطغى

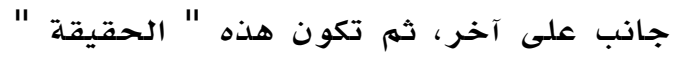

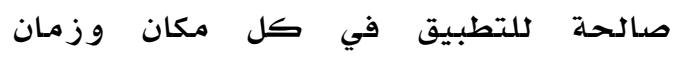

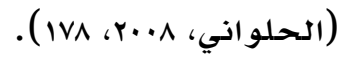

إن من أهم مبررات عملية التأصيل الإسلامي

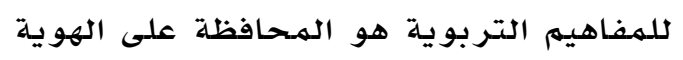

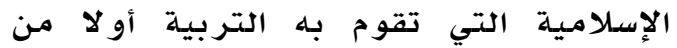
خلال إعادة صياغة الفكر التربوي الصوي الصحيح في ضوء مصادر التربية الإسـلامية، وهو ما

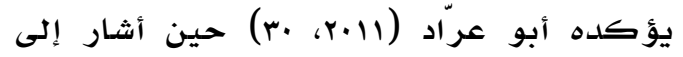

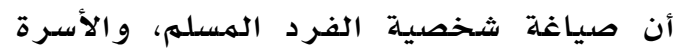

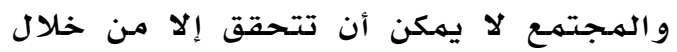

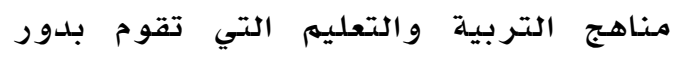

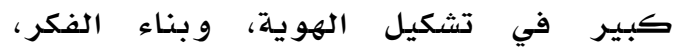
و تحديد معالم الشخصية المسلمسة المستقلة.

أهداف التأصيل الإسلامي للعلوم التربوية: الهدف الأساسي للتأصيل الإسـلامي للعلوم

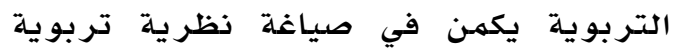

مبررات التأصيل الإسلامي للمفاهيم التربوية

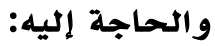

بناء المفاهيم يعد جزءا من مهممة مهمتدة

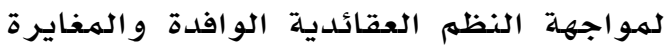

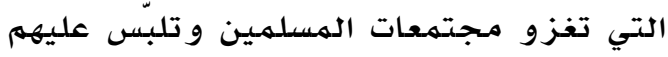
دينهم، وتعد كذلك جزءا أصيلا من نظام

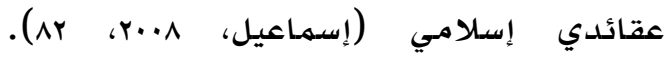

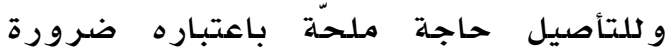
عصرية، فنحن في العصر الحديث نعيث

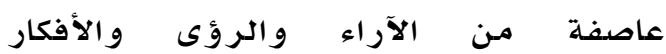
و النظريات، و لا يمكن لنا العيش مـن غير

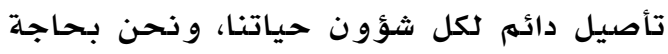

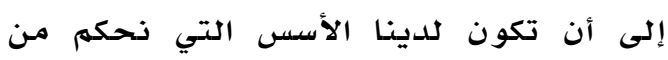
خلالها على هذه المفاهيم، وأن تكون لدينا

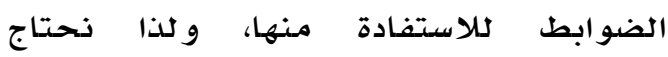
للتفكير الناقد، و عملية التأصيل هي مهمارسـة

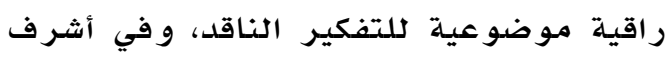

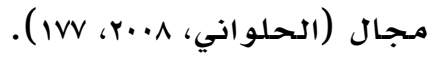

ويحدد العمرو (r........ (ro) مبررات تأصيل

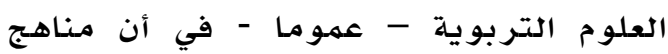

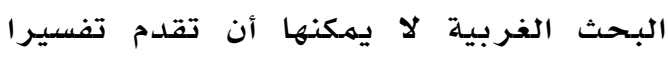

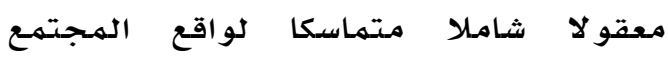
الإسـلامي الذي يختلف عن المجتهـع الغربي في جوانب حياته المختلقة تربويا و اجتهاعيا

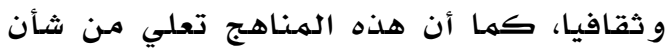
الدوافع المادية وتهمل الدوافع الروحية في

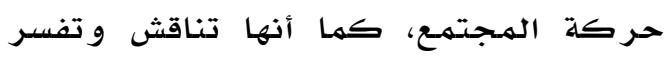

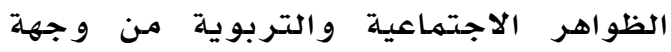
نظر غربية بحته، تجعل الحضارة الغربية هي المحور وتهمل الحضارات البشرية

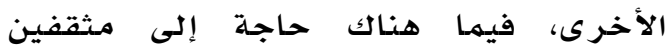

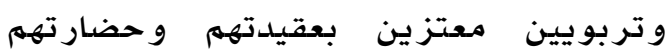
وثقافتهم الإسلامية التي ينتهمون إليها، وتعميق شعور الاعتزاز بها في طلابهم

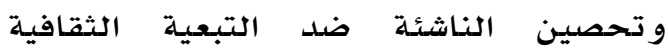

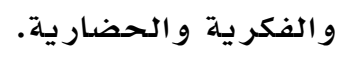

وهو هنا ينطلق من مبدأ الاختلاف الفكري

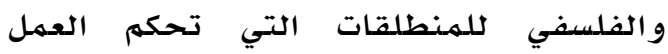
التربوي في المجتمعات عمومـا، وهو مبدأ 
الإسـلام العامـة و مبادئه الكلية الاعتقادية

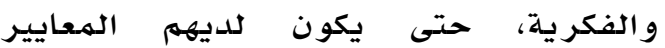

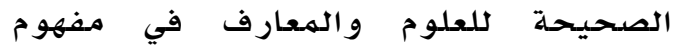
الإسلام، وتتكون لديهم ملكة النقد النزيه

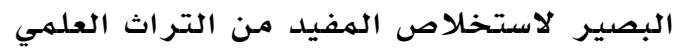

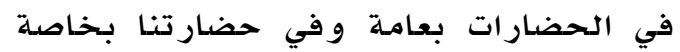

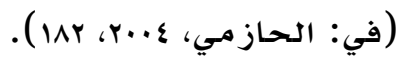

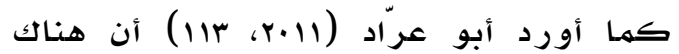

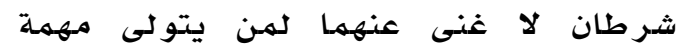

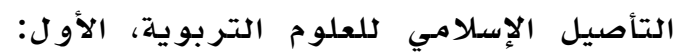
يجب أن يكون المشتغل في هذ الديلا المهال

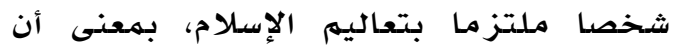

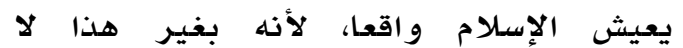

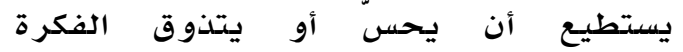

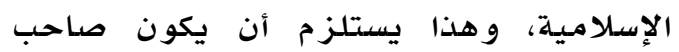

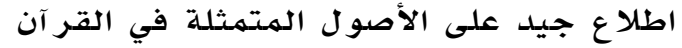

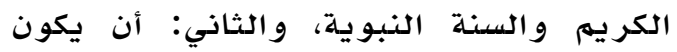

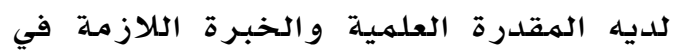
الفن الذي سيكتب فيه.

إلا أن هناك معوقا يقف أما تلك الهـحاو لات

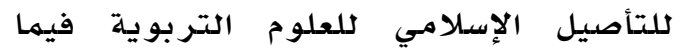
يتعلق بتوفر هذه الشروط، حيث إننا قلما أن نجد متخصصسا في فرع مـن فروع التربية

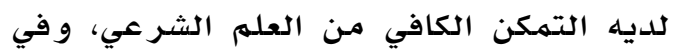
المقابل قد لا نجد من لديه تمكنا في العله

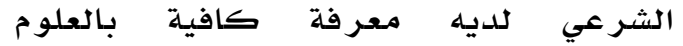

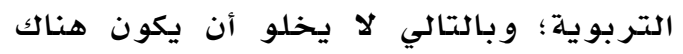

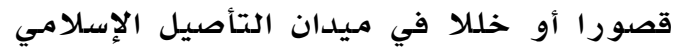
للعلوم التربوية إن له يكن هناك تنسيق بين

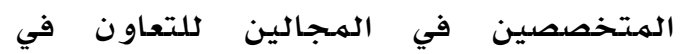
تحقيق أهداف عملية التأصيل الإسـلامي للعلو م التربو اهيقة

ثانيا: معايير التأصيل الإسلامي للمفاهيم

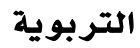

عند النظر إلى الأدب التربوي، يرى الباحث

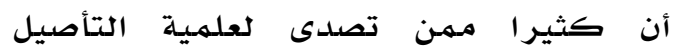

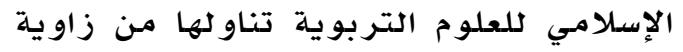
كلية، وومن ذلك ما أشار إليه النقيب (ع......

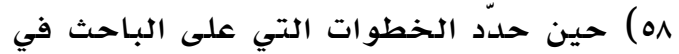

إسلامية تنطلق من مصادر التشريع

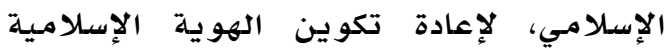

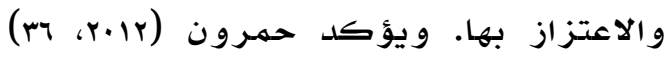

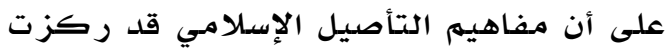
على إبراز الأسس التي تقوم عليها العلوم مـن

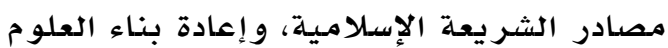
و تكييف المعطيات و المنجززات وفق المنظور

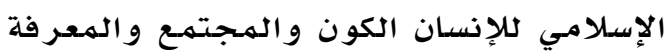
و القيهم و العلاقة بين كل منها، ورفض إقامـة

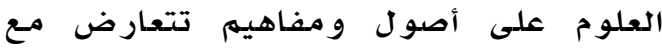

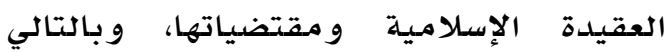
استخدام منهج يتكامل فيه الوحي الصحيح مـع الواقع الهشاهد لبناء النظريات في العلوم

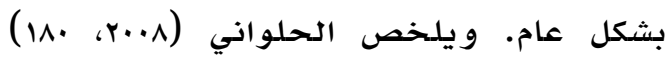
أهداف التأصيل الإسلامي للعلوم التربوية في هدف نهائي يتمثل في: إيجاد نظرية إسـلامية لكل فرع من فروع العلوم المـختلفة، تتوافق إنق

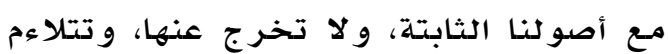

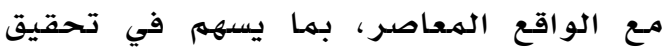

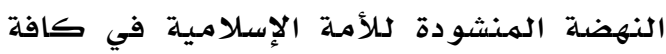

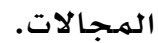

الشروط الواجب توفرها فيمن يتصدى للتأصيل الإسلامي النوومي

تناول العديد من الههتمين بادتأصيل الإسـلامي الشروط التي ينبغي توالفرها الباحث في هذا الميدان، حيث ذكر إكر الفاروقي

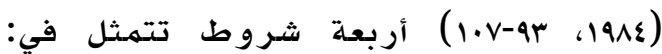

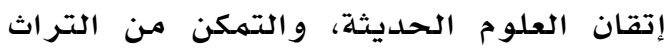
الإسـلامي، وتحلديد المشكلات المهمهة لكلأمهة،

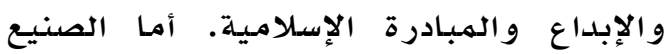

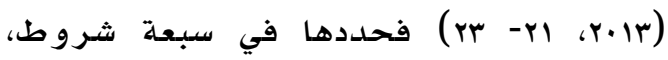

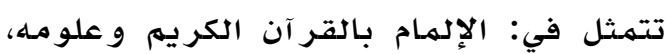

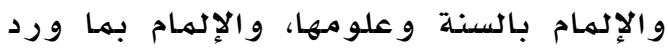

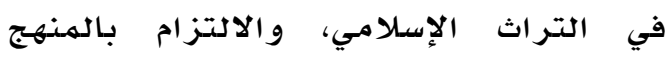
الإسـلامي اعتقادا وقول و وعملا، والإلمام

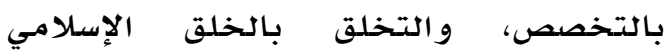

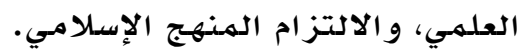
إنّ المعنيين بالتر بية وبالتو جيه الإسلامسي من

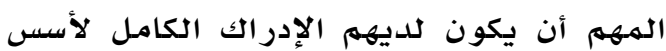


في ضوء مقتضيات ذلك التصور

الإسـلامي، سواء مـن حيث الموضوض منهو أو

الهـنهج

1ا. بناء نسق علمي متكامل يضمر مـا صـح

من نتائج العلوم الحديثة، ويريط

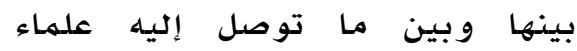

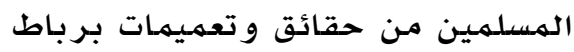
تفسيري مستمد من التصور الإسلامي.

rا. استنباط فروض مستمدة من ذلك

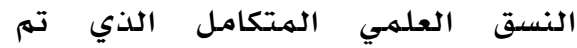

التوصل إليه فيما سبق، و إخضاع تلك

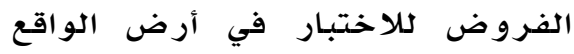

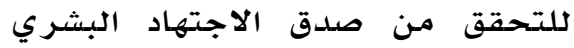
المتضمن بالضرورة في عملية بناء أي نسق علمي نظري.

فيما اقترح الصفدي (1994، البا ) عددا من

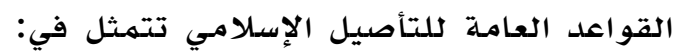

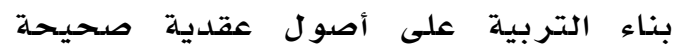

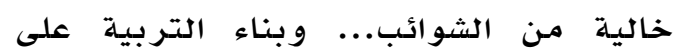
أصول تطبيقية سليمة تترجم العقيدة إلى

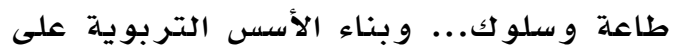

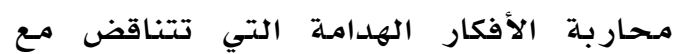
عقيدة المسلمه...

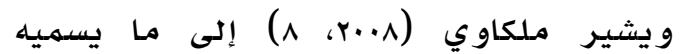

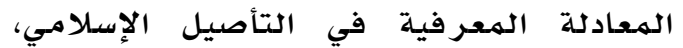

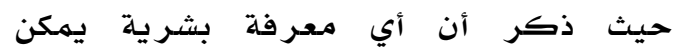
للمسلهم أن يتبنّاها سوف تأتي من مصدئ مصرين، هما: الوحي و الكون، وعن طريق استخدام

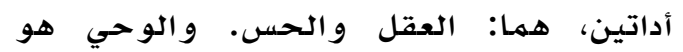
القر آن الكريم وهو الهصدر الهـنئ، والسنة

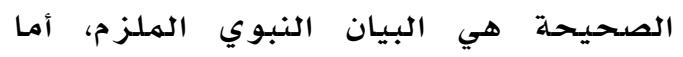
الكون فيمكن أن نميّز فيه ثلاثة عناصر

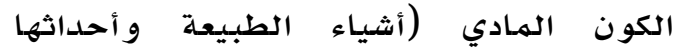

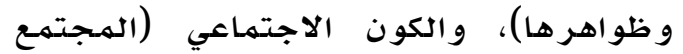

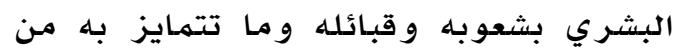

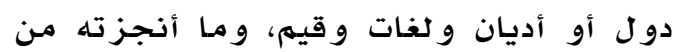

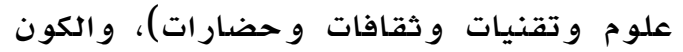

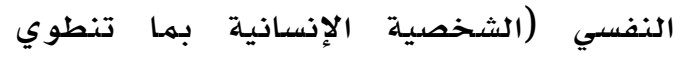
عليه: جسهم وعقل وروح، ووما تمتلكه من لإسيه
أصول التربية أن يسترشد بها عند التصدي للتأصيل الإسـلامي، وهي:

1. جمـع النصوص الإسلامية المتعلقة

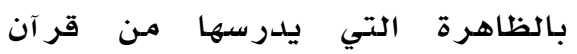
وصحيح سنة.

r. فهم النصوص فهما صحيحا، والتأكد

من معرفة دلالة النصوص بالعودة إلى

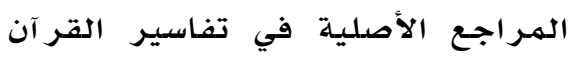
وشروح الحديث.

r. الدراية بمصادر الهعرفة الإسدلامية

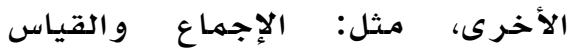

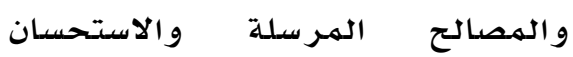
و والعرف

ع. الرجوع إلى التراث الإسلامي و آراء

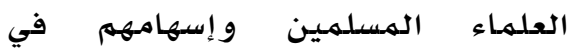

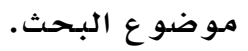

ه. الاستفادة من التطبيق التربوي في

$$
\text { عصر النبوة. - مصادة من }
$$

T. الاستفادة مما وصل إليه العلهم في

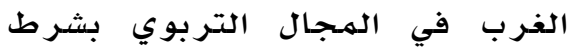

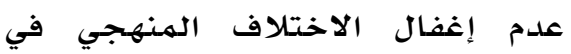
تناو ل الظاهرة. V. الاجتهاد التربوي في تنزيل ذلك الك الكعاث

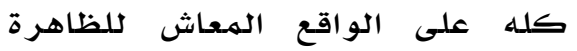
التربوية المدرروسة. ^. وأكد رجب (1997، عا ) على أن

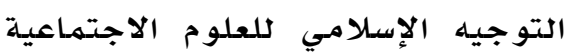
يتضمن المكونات أو الأركان الآتية: 9. تحديد أبعاد التصور الإسـلامي الشـامل

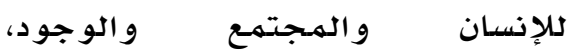

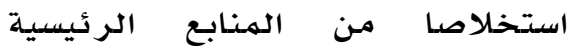

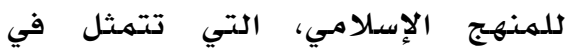

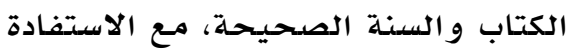

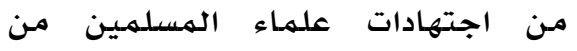
السـلف و المعاصر ين. •1. حصر نتائج البحوث العلمية ومستح نظر ياتها و تحليلها و إخضاعها للنقد 
الأساسيان في الشريعة الإسلامية و وبالتالي

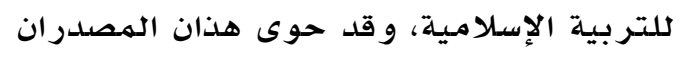

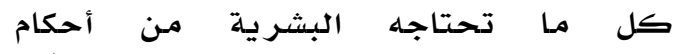

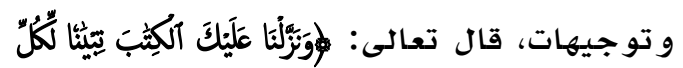

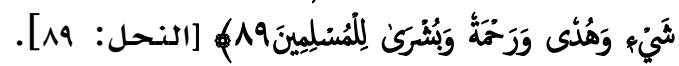

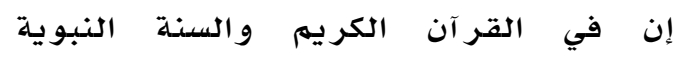
توجيهات تربوية عظيمة لتربية الإنسان

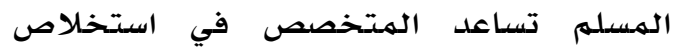

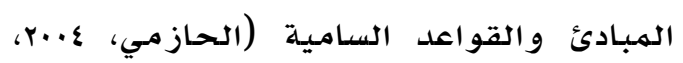
. (11.

و المسلّمات التي هي موضع اتفاق عند عدد التئ

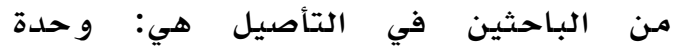
الحقيقية، فلا توجد حقيقة علمية وأخرى

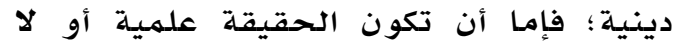
تكون، بغض النظر عن مصدرها، والمسلمة اندان

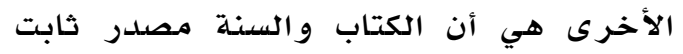

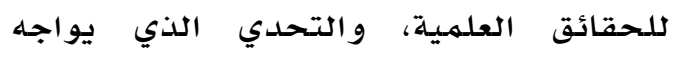

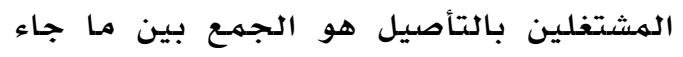

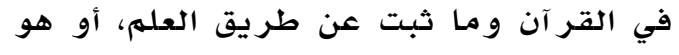
توظيف هاتين الهسلمتين في البحث العلهي

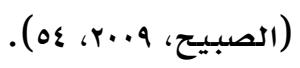

إن ببناء التصورات والأسس العقيدية التي

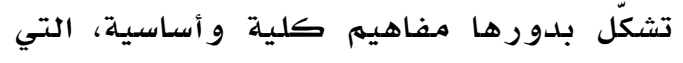

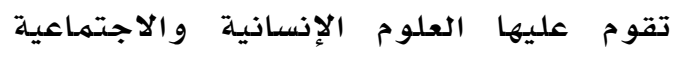
والسياسية يجب أن تستند إلى الهون المفاهيم

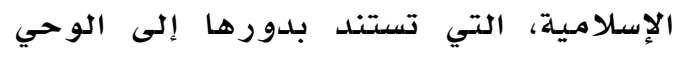

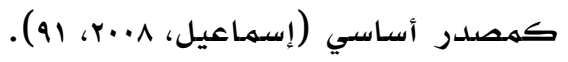

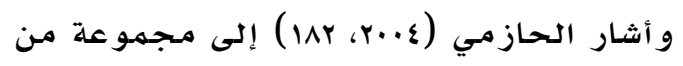

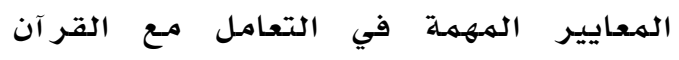

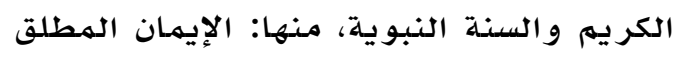

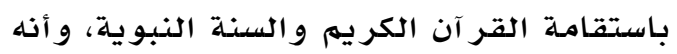

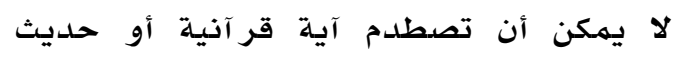
صحيح مـع سنة كونية، لأن مصدرهما الله آلها تعالى، وعدم إخضاع نصوص القر آن الكريم

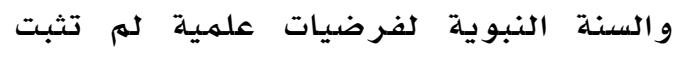
صحتها، وعدم إسقاط المعتقدات والآراء

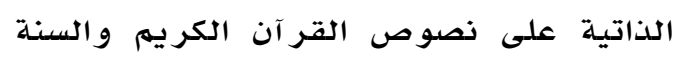

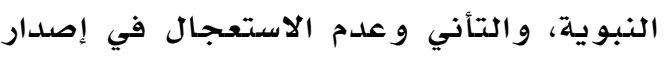

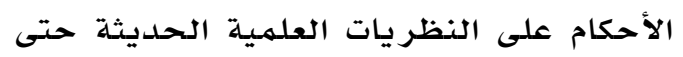

\section{معار ف و مهار ات و انفعالات...).}

ولضمان نجاح عملية التأصيل الإسلامي

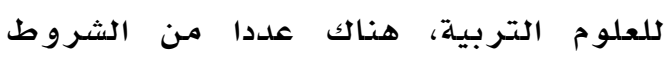

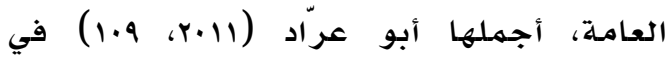

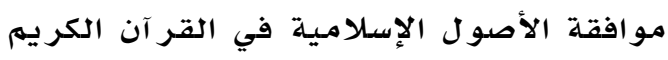

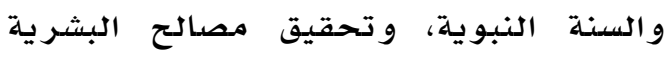

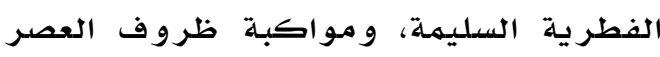

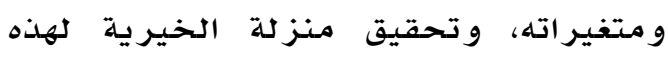
الأمة حتى تكون شاهدة على الأمم الأخرى.

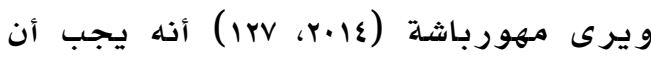

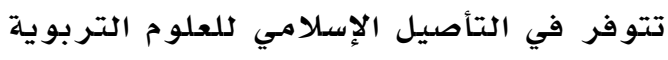

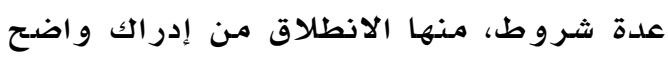
لأبعاد التصور الإسلامي أو الرؤية الإسلامية الإنية

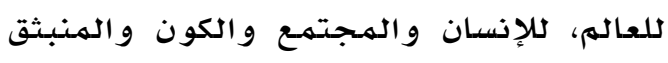

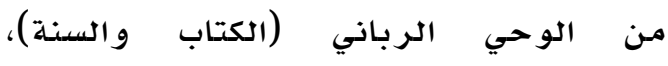
واستيعاب العلوم الحديثة في أرقى صورهانيا،

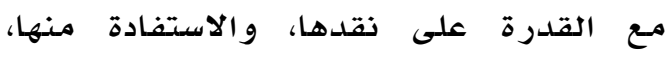

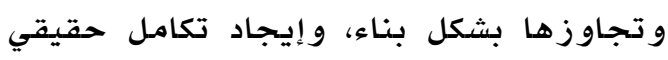

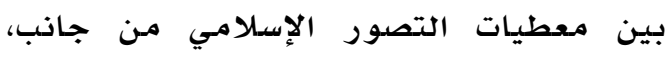

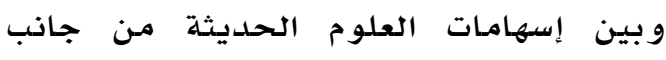

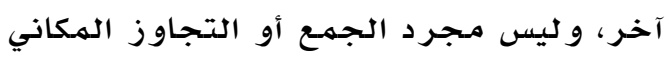
أو حتى المزج بينهما دون وحدة مجردية الجيقية. وهناك اتجاهان رئيسان للتأصيل الإسبلامي

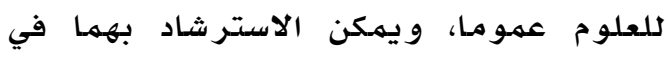

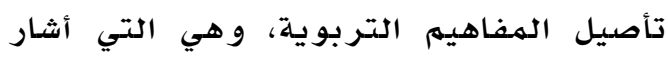

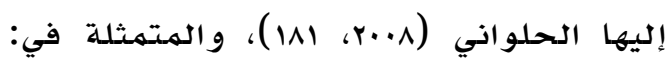

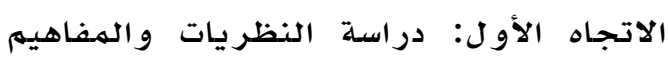

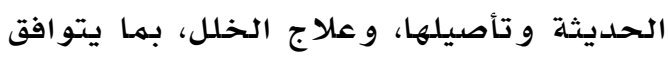

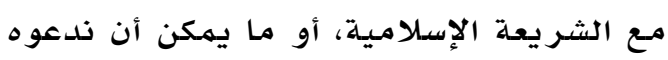

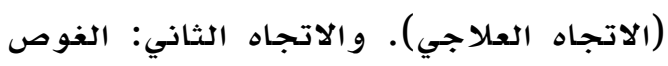

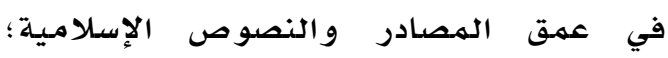

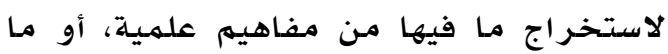
يمكن أن ندعوه (الاتجاه البنائي). وبناء على ما سبق يمكن للباحث أن يحدد معايير التأصيل الإسلامي للمفاهيم التربوية

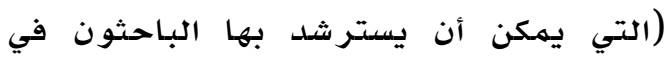

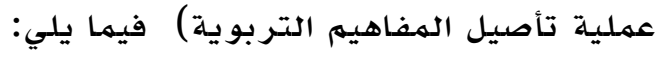
الاعتماد على مصادر التربية الإسلامية: القر آن الكريم والسنة النبوية هما المصدران الإنيان 
الاستعانة بالتفاسير القر آنية وشروح

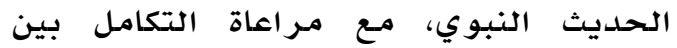

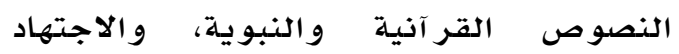
التربوي في تطبيق النصوص لاستنتاج العناصر الرئيسية لقضيلة المـر اد تأصيلها، مـع الاستعانة بها توصل إليه العقل الإنساني الهريه

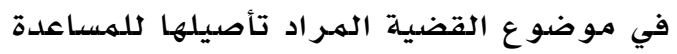
في فهم المر اد الإلهي مـن النصوص.

القدرة على نقد مرويات التراث والتعامل معها: ويتأتى ذلك من خلال المعرفة الكافية

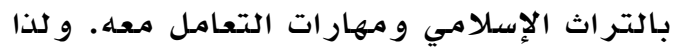

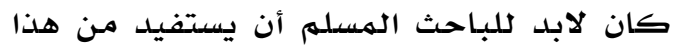

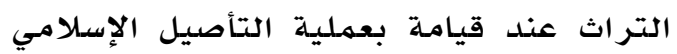
للمفاهيم بحيث يرتكز على أسس راسختة في بيانها و فهمها و تطبيقاتها التربويلة. والتأصيل الإسـلامي للعلوم هو إبراز الأسس

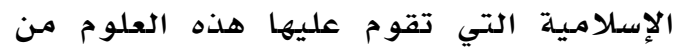

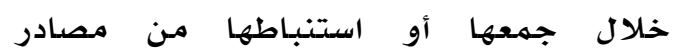
الشريعة وقواعدها الكلية وضدوابطها العامـة، مدها

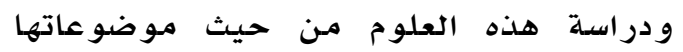

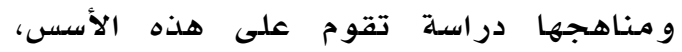

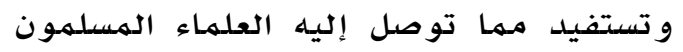

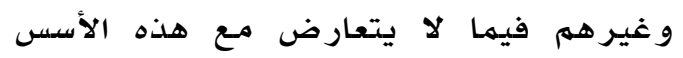

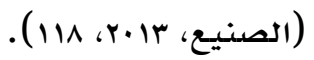

فهم ومعرفة الساليب اللغة العربية واستخداماتها المتعددة: العربية لغة القر آن الكريم و لغة النبي صلى الله عليه و سلهم، و لا يمكن أن يتحقق التأصيل الهيل

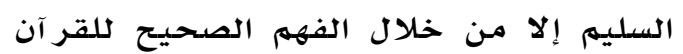

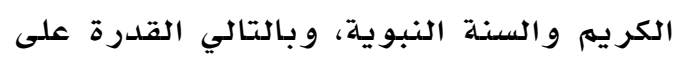
استتباط المبادئ التربوية وتئه وتأصيلها. و اللغة هي أداة التفكير، كمها أنها أداة البيان، وارتباط الأداة بالمصدر: ارتباط لا ينفصه؟

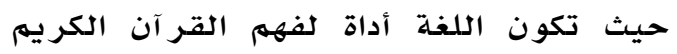

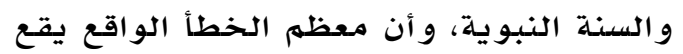

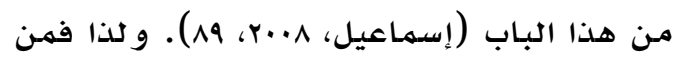

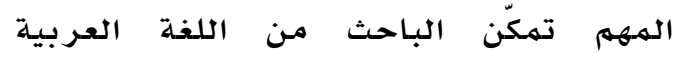

يتم التأكد من صحتها و صدقها.

الالتزام بقواعد الاستنباط والاستدلال في

المنهجية الإسلامية الإمزام

بحيث يتمكن الباحث من الوصول إلى النتيجة الصحيحة في ضدوء منهجية لهنية علماء الشريعة والأصول في دراسـاتهم.

ويقوم التأصيل على ثلاثة متطلبات أسـاسية لا يُغني أحلدهما عن الآخر ، المتطلب اهلب الأول:

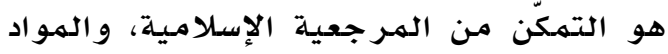

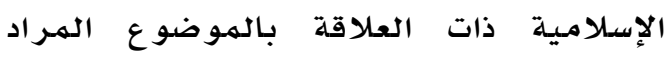

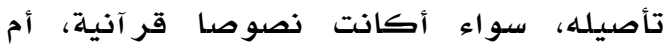

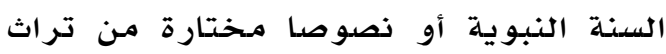

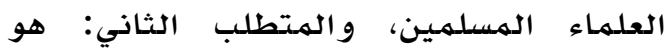

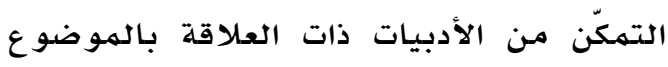

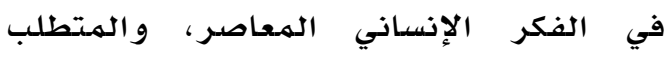
الثالث هو القدرة على الجمهـع بين نتائج

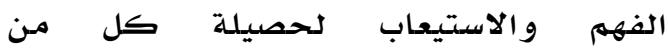
المتطلبين السابقين، وومن ثم القيام بقفزة

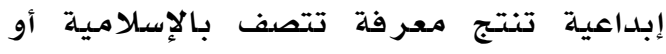

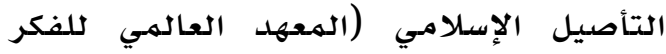

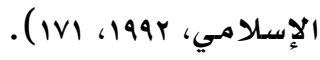

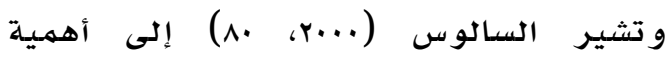
تحديد منهج للتأصيل لأنه يحدد معالم

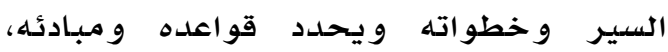
و أنسب تلك المناهج المنهج الأصولي في ولي العلوم الإنسانية، والذي ميعني استخدام

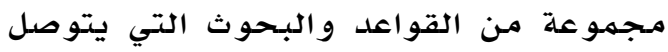

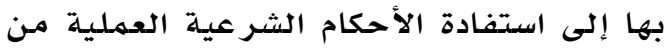

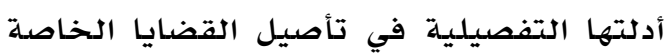
بالعلوم الإنسانية ومنها التربية، و هذا المنهج يتكون من: التحديد الدقيق للقضية المـراد تأصيلها، وذلك في سياق فهم واع بطبيعة هذه القضية وتحديد دقيق لمفاهيهها

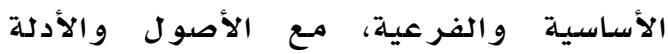
المسداعدة على تحديد أبعاد القضية التي

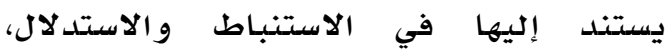

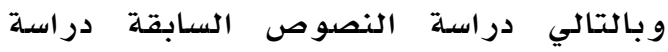
متأنية تتسهم بالاستيعاب و والتعمق و والدقة درة

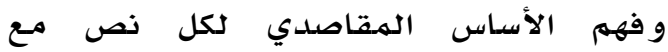


و الحياة، و اختلاف الثقافات، و تعدد الهنطلقات

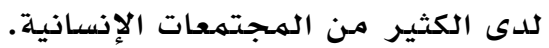

إن التصور السليه للعقيدة يدور حول التوحيد، وهو القاعدة والمنطلق الذي أرسل الذله

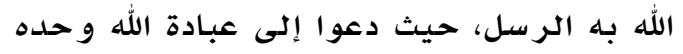

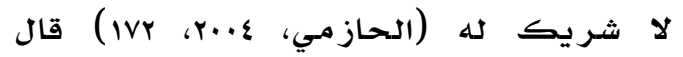

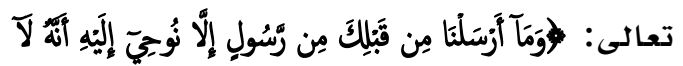

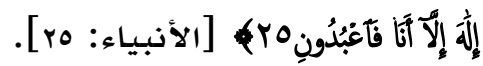
وكذذك تبدو الأهمية في تحديد الهفهوم في وصله بالعقيدة، بل وانبثاقه منها ابتداء

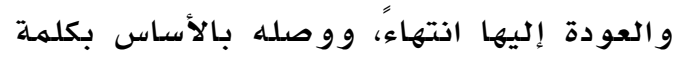

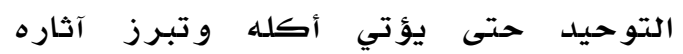

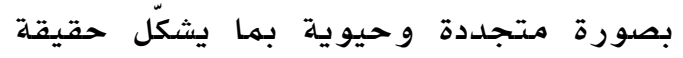
جوهر عملية التجديد على المستوى الفكري

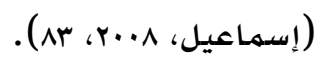

المعرفة الواسعة بالميدان التربوي والعمل ضمن حقله:

على الباحث في التأصيل الإسلامي للعلوم

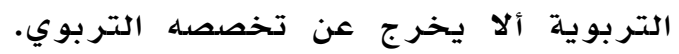

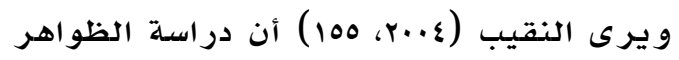

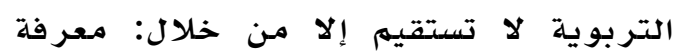

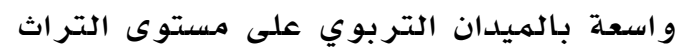

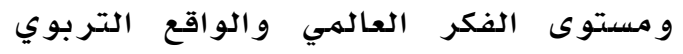

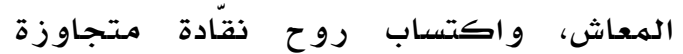
لتلك المعارف قادرة على الأصدالة والإبداع، الماعل وامتلاك المهارات البحثية المتعارف عليها بين علماء التربية، كل ذلك من خلال روح

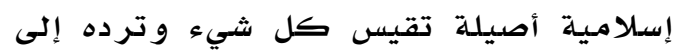

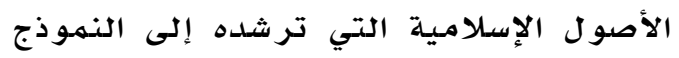

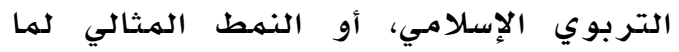

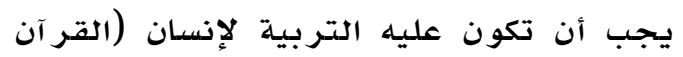
و السنة) في هذا العصر .

عرض المفاهيم التربوية بوضوح بعد تأصيلها:

إن الرؤية الإسلامية التي تتميز بالكلية

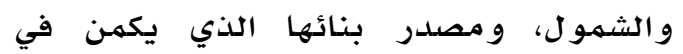
دلالات نصوصها، تتضهن مفاهيم أساسية منهجية تنتظم على أساسها مكتسبـات الإنسان
و علومها إذا أراد أن يتصدى لعملية التأصيل الإسـلامي للهفاهيه.

التمييز بين مصادر المعرفة في الإسلام وعند الأمم الأخرى:

فهي ربانية الهصدر في المنظور الإسـلامي، بشرية المصدر في منظور الأمهم الأخرى، و التمييز يكون في ضوء هذا الهـا الهعيار. و وقد

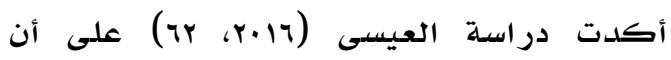
البـاحثين في مجال التأصيل الإسـلامي للعلوم

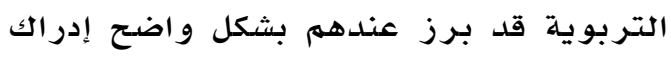
التصور الإسـلامي للإِنسان و المجتمـع و الكون

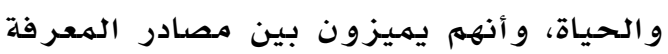

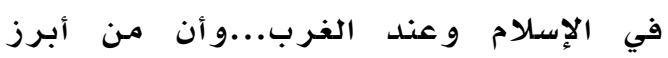
جوانب الضعف لدى الباحثين في هذا الهـال

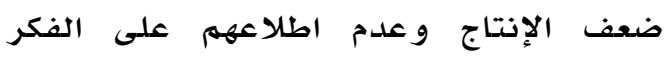
التربوي الغربي... كها أن واقع الهحتوى التها لبحوث التأصيل الإسلامي للعلوم التبري التربوية

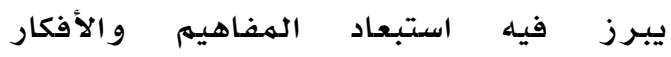

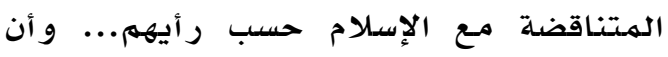
هنالك ضعفا في تناول النظريات التربوية الغربية و الإسلامية على حد سواء.

إن الدواعي الأساسية لإعادة بناء العلوم

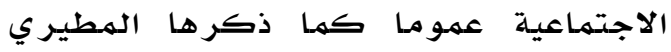

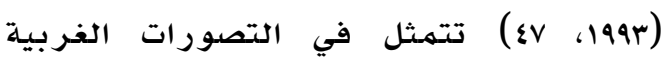

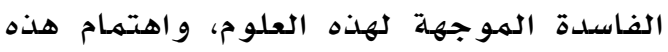

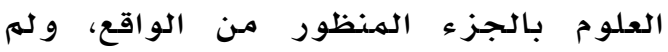

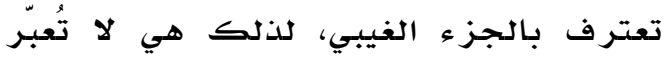

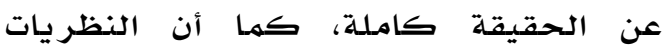

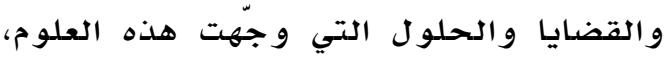
هي قضايا تخص بالدرجة الأولى العالم الغربي، وومن الخطأ تعميهها على بقيلة أنحاء العالهم.

الانطلاق من التصور الإسلامي للكون

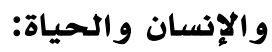
من الههم للباحث المسلهم أن يتخذ العقيدة الإسلامية منطلقا له في ميدان الهان التأصيل الإسلامي للمفاهيم التربوية، فهي الهمرجيع

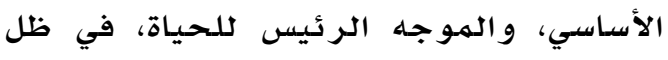
تباين التصورات نحو الإنسان والكون 
الدعوة إلى إعادة بناء مناهـج البحث و التحليل

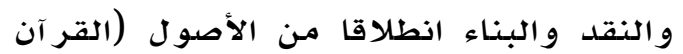

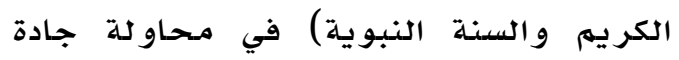

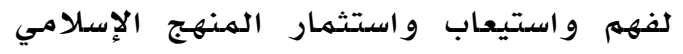
في معالجة المشكلات و والقضايا المرتبطة بالإنسان و الكون (انمير ات، 1999، 1••1).

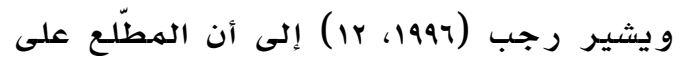

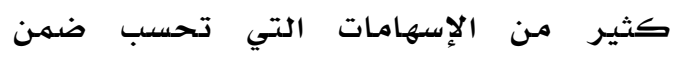

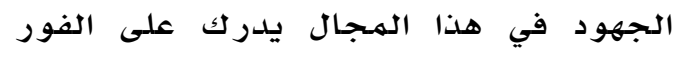

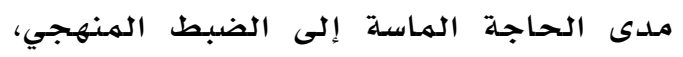

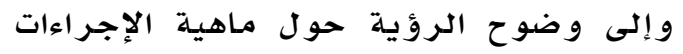

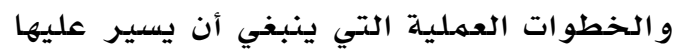

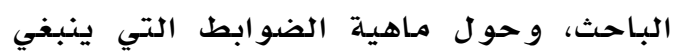

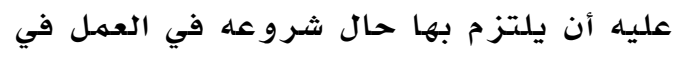
بحوثه في هذا الهـجال.

الوسطية في التعامل مـ المفاهيم التربوية الوافدة من الثقافات التربوية الأخرى: إن عملية توضيح المفاهيم بالمعنى الذي

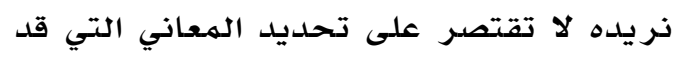
يدل عليها المفهوم تحديدا يحول دون وقوع اللبس و الغموض، و إنها تتسع هذه العملية بحيث تشمل الكشف عما تتعرض وله له الهفاهيه في حالة تخلف الأمة عن الركب الحضاري

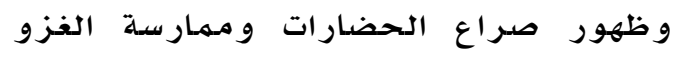
الفكري للحضارة الغالبة على الحضارة

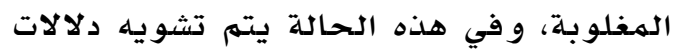

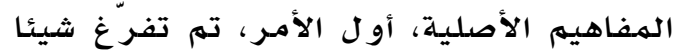

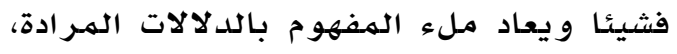

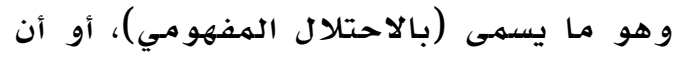
بعض المفاهيم تتبادل المر اكز بحيث يصبح

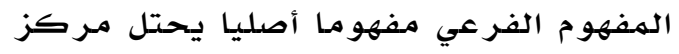

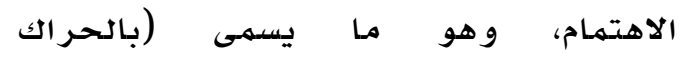

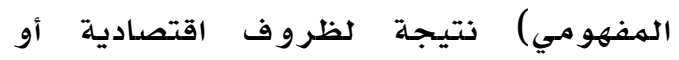
اجتماعية تمـر بـه الحضارة في حالة ضعفها

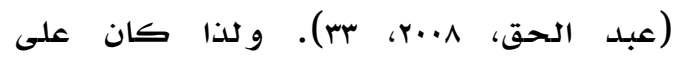

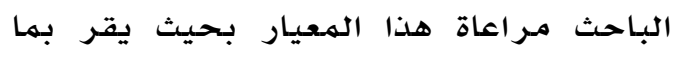
جاءت به من الحقائق دون تحيز أو تهميش. مراعاة جوانب الخلاوف الشرعي وانعكاسله على التطبيقات التربوية:
الهعرفية في كل مجال من مـجالات النظر والتطبيق، وليست هذه الدلالات (في إطار عملية بناء المفاهيه) حين يتوصل وصل إليها بناء" معرفيا فحسب، بل هي منظومة من المقاييس

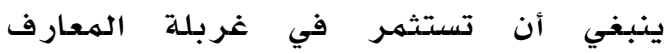

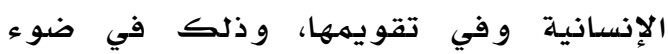

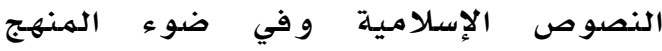
الإسـلامي الذي يصدر عن النصدوص الإسـلامية

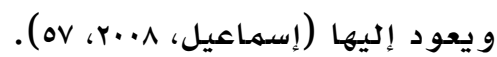

يجب صياغة المفاهيم الإسلامية الأساسية بحيث تكون هذه الصياغة محكمة البناء منضبطة المعنى، قادرة على مواجهة النظم الأخرى وومخاطبة الناس جميعا بالمفاهيم

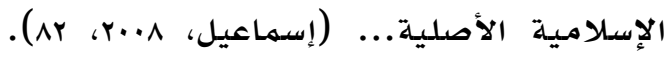
فهن الههم النه يكون الباحث في ميدان

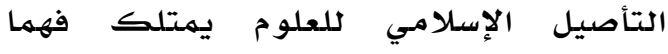
للعلوم و المعارف متصفا بالشمول و التكامل،

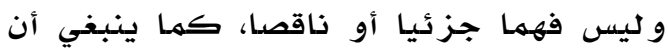
يكون طرحه طرحا شاملا و متكاملا و وليس اونس

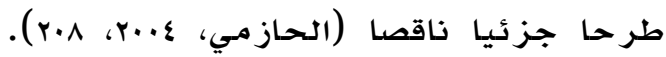

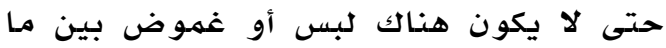
تم تأصيله من مفاهيم وبين ما هو هو موجود في الثقافات الأخرى.

التحقق من اهداف التأصيل للمفاهيم

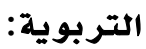

فتكون عملية التأصيل في ضوء تلك

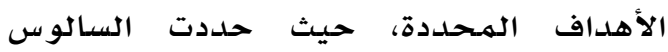

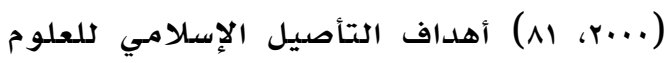
التربوية، و أكدت على تنقية العلوم التربوية التهالية مها شابها من تصور ات ومفاهيم تتعارض مـع

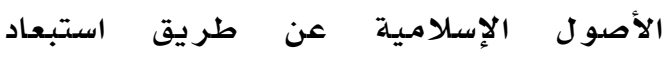
المفاهيم والأفكار الوافدة المتناقضة ولعيه ولعليل تلك الهفاهيم في ضوء معايير التأصيل الإسلامي للعلوم التربوية الهمئة

بروز معالم ومنهجية التأصيل الإسلامي عند تناول المفاهيم التربوية: إن التأصيل الإسلامي للمعارف والعلوم

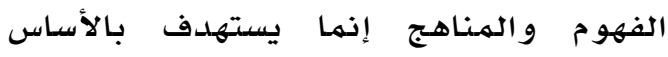




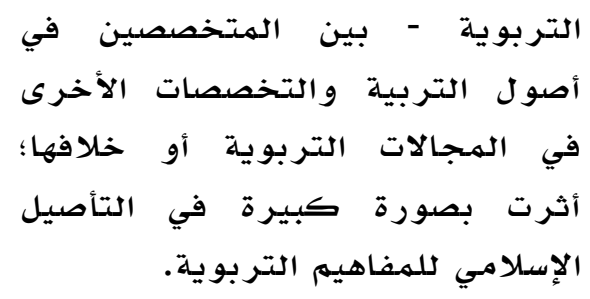

منهج التأصيل الإسلامي للعلوم الاجتماعية هو القواعد والطرق التي تطبق في دراسة

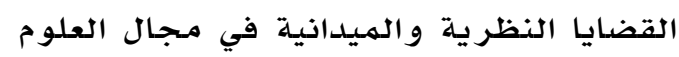

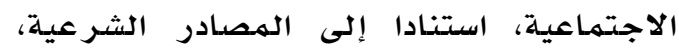

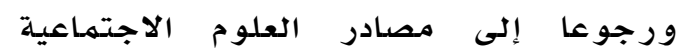

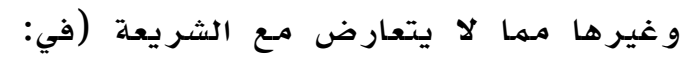

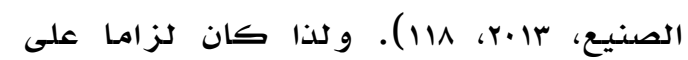

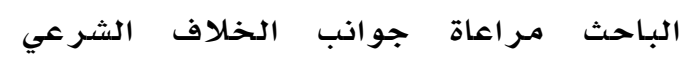

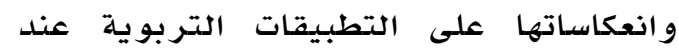

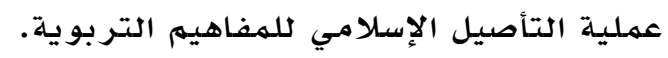
إن مراعاة هذه المعايير لدى الباحث التربوي

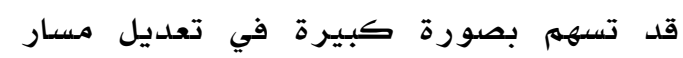

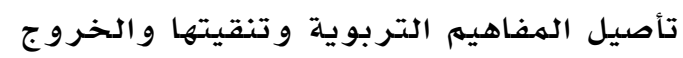

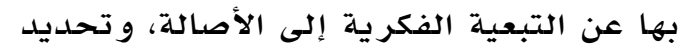

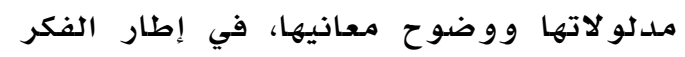

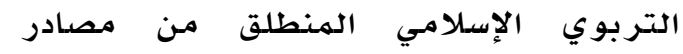

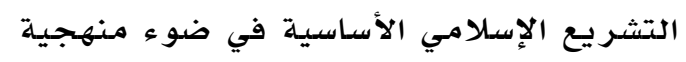

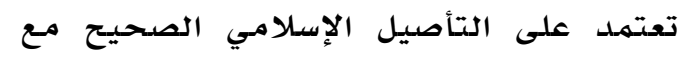

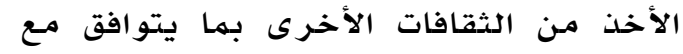
ثقافتنا و لا يتعار ض مـع هويتنا الإسلامية.

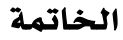

تناول الباحث في هذه الدراسة معايير

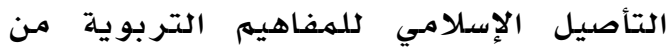
خلال مناقشة المقصود بالمفاهيم التربوية الإسية

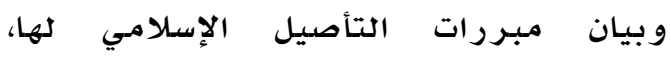

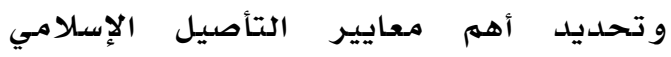

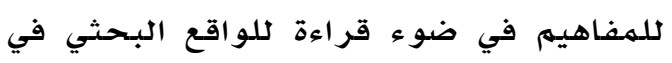

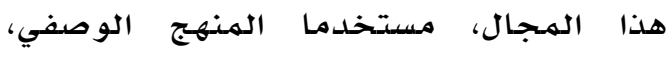

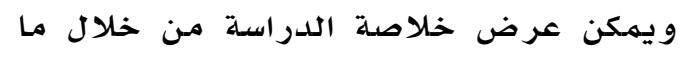

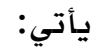

\section{نتائج الدراسة}

توصلت الدراسة إلى النتائج التالية: 1. أن هناك تفاوتا في صياغة معايير

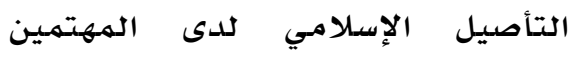

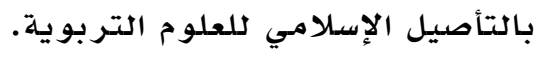
r. أن غياب الدراسات البينية - التي قد

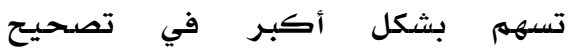
منهجية التأصيل الإسلامي للعلوم تلعير 
و الإثكالية، مجلة المصباحية، سلسلة

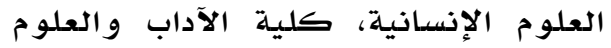

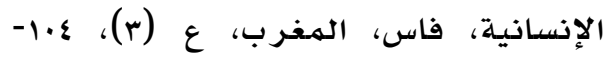

.111

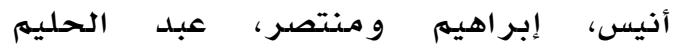

و الصوالحي، عطية و أحمد، محمد الهر خلف

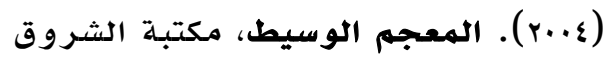

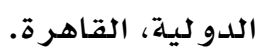

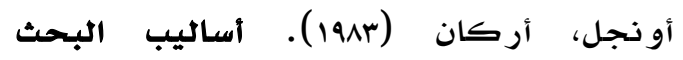
العلمي، دراسة مفاهيم البحث لأخصائي العلوم الاجتماعية، ترجمـة: حسن ياسين، معهد الإدارة العامـة، القاهرة.

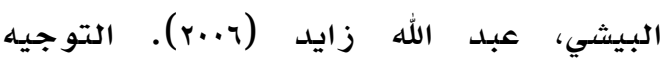

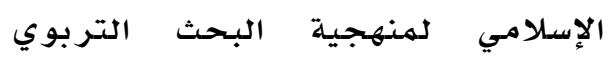

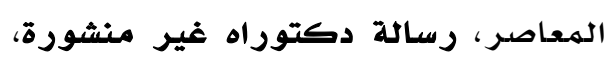

قسهم التربية الإسلامية والهقارنة، ولهية كلية

التربية، جامعة أم القرى، مككة المكر مـة.

الجمل، علي، و اللقاني، أحمد (1997) ). معجم

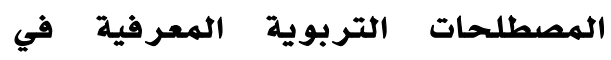

المناهج وطرق التدريس، عالم الكتب،

القاهرة. - اهمر

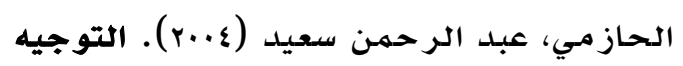

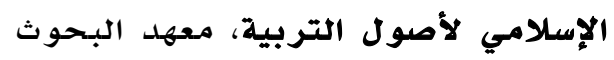

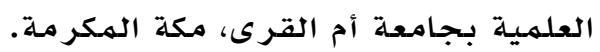

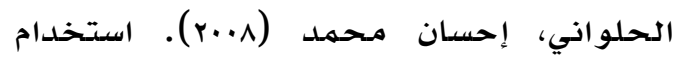

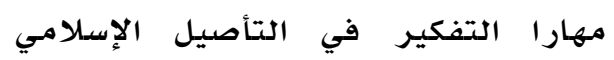

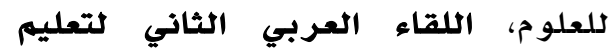

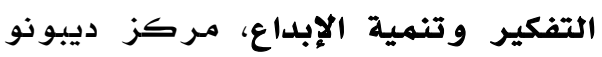

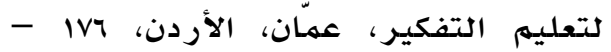

$.19 V$

حمرون، ضيف الله غضيان (Y.r.r). التأصيل

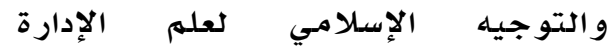

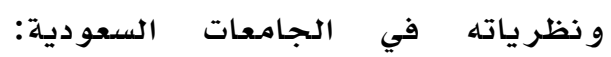

تصور مقترح لتوجيهه إسلاميا، مجلة الجهالة

جامعة الإمام محمد بن سعود - العلوم

الإنسانية و الاجتماعية، الرياضة الأمام، مجمد ع (rr)،

$.01-14$ r. تفعيل معايير التأصيل الإسدلامي

للمفاهيم التربوية من خلال مقررات

مناهج البحث التربوي في أصول

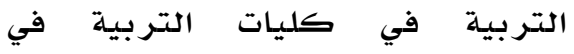

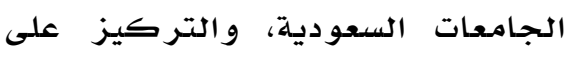

الجانب التطبيقي من خلالها.

مقتر حات

في ضوء نتائج الدراسـة يقترح الباحث إجراء الدر اسـات التالية:

1. دراسـة تحليلية للدراسات التأصيلية

التربوية في ضدو ضدو معايير التأصيل

$$
\text { الإسـلامي للتربية. }
$$

r. الجهود التربوية في مجال التأصيل

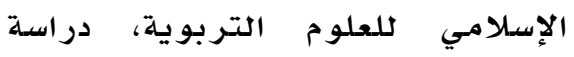

تقو يمية.

r. بناء المفاهيم في الدراسات التربوية، در اسـة نقدية.

\section{المر اجح}

\section{References}

ابن منظور، أبو الفضل جمال الدين (199)). لسان العرب، طم، دار صدادر، بيروت.

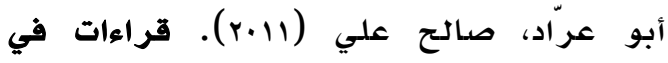

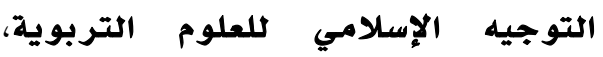

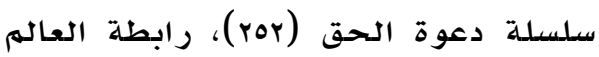
الإسـلامي، مكة المكر مـة.

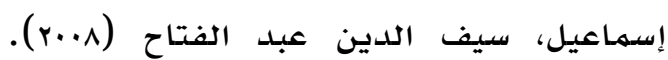

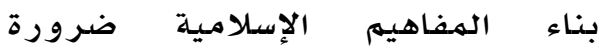

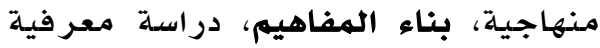

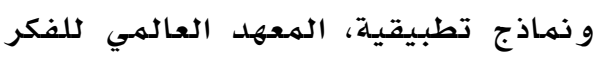

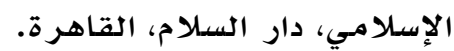

إسـماعيل، سيف الدين عبد الفتاح (^) (ب).

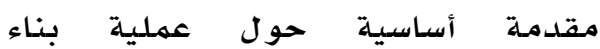

المفاهيم، بناء المفاهيم، دراسـة معرفية آمهية

و نهاذج تطبيقية، الهعهد العالهي للفكر لهمر

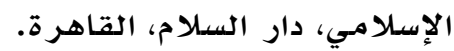

انميرات، عبد العزيز (1999). التأصيل

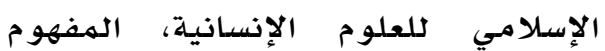


ثؤون اجتماعية، جمعية الاجتماعيين، بو . lov - Irv، ( $1 \mathrm{v})$

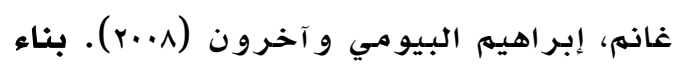

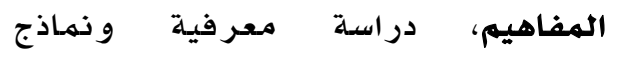

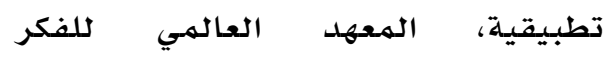
الإسـلامي، دار السـلام، القاهرة.

الفاروقي، إسماعيل (عب191). أسلمة المعرفة، الهبيادئ العامـة وخطة إسهاعيل العمل، دار البـحوث

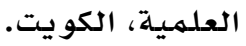

المطيري، منصور زويد (1999). الصياغة

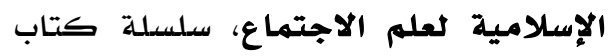
الأمهة (سب)، وزارة الأوقاف والأهؤونة

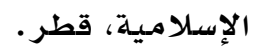

المعهد العالمي للفكر الإسدلامي (199r). إسلامية المعرفة: المبادئ وخطة العمل و الإنجازات، فرجينيا، أمر يكا.

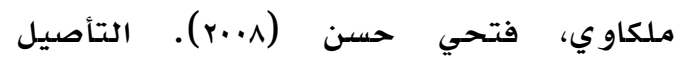

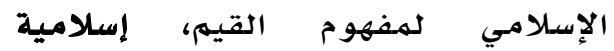

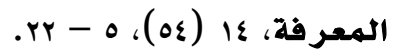

الهيمان، بدرية صالح (r..r). نحو تاصيل

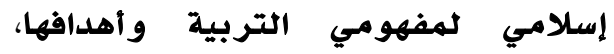
رسالة دكتوراه منشورة، دار لمعي ماله الكتب، الر ياض. - اض.

نوفل، محمدد نبيل (1910). دراسات في الفكر التربوي المعاصر، مكتبة الأنجلو المصرية، القاهرة الترئ

هاشه، رضا محمد (rا.r). واقع البحث

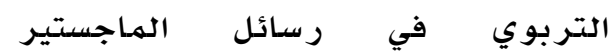
والدكتوراه في مجال أصول التربية

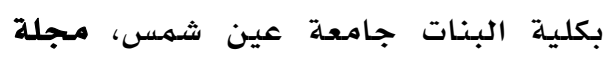

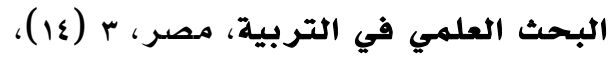
$.01 \cdot-\Sigma 79$

يالجن، مقداد (عا.r). اساسيات التأصيل والتوجيه الإسعلامي للعلوم والمعارف والفنون، دار عاله الكتب، الرياض.
خليل، عماد الدين (.199). مدخل إلى إسلامية المعرفة، المعهد العالهي للفكر الإسـلامي، فر جينيا، أمر يكا. رجب، إبر اهيهم عبد الرحمن (1997) ). التأصيل الإسلامي للعلوم الاجتماعية: معالهم على إلى

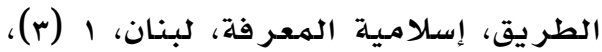
$. \wedge r-\varepsilon V$

سعادة، جودت أحمد (.199). مناهج الدراسات

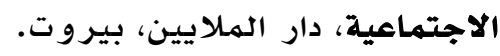

الصبييح، صالح إبراهيم (rا+r). المدخل إلى

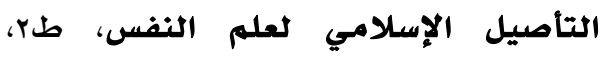
مكتبـة الرشد، الرياض. الصفدي، أحمد عصام (1994). أصدول التربية

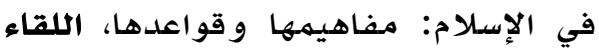
السنوي الخامس (التاصيل الإسلامي للتربية وعلم النفس) الجمعية السعودية الجمية التهيل

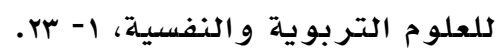

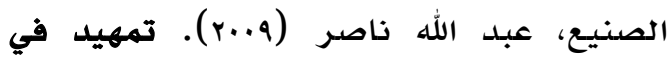
التاصيل رؤية في التأصيل الإسلامي لعلم النفس، طب، دار كنوز أثبيليا،

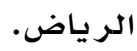

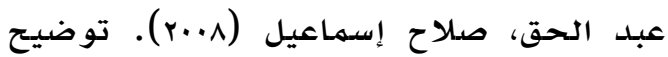
المفاهيم ضرورة معرفية، بناء المفاهيم،

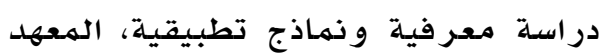

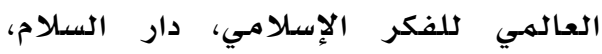

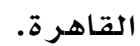

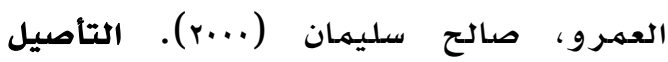
الإسلامي لفلسفة التربية، معهد البحوث العلميهة، جامعة أم القرى، مكة المكر مـة. العيسى، إبر اهيهم محمدد (17) (r). و اقع بحوث

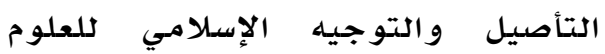
التربوية في جامعات المهملكة العربية الإسية

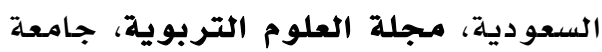

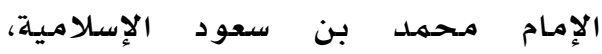
الرياض، ع (v)، الإمام

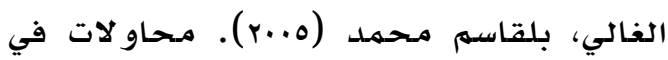

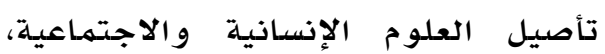

